ferner, dass die beiden ceteris paribus mit Steigerung des Abstandes der secundären Spirale viel rascher verschwinden als die 3 andern, a, e und 0 . Ein weiterhin nicht zu unterschätzender Einfluss der resonatorischen Bedingungen der benutzten Membranen bez. Platten besteht hinsichtlich der Uebertragung und physiologischen Wirkung gleicher Laute bei verschiedener Höhe des Grundtons. Es zeigten verschiedene Versuche aufs dentlichste, dass anch dieser Faktor einer ausgiebigen Verwéndung von Mikropbon und Telephon von jetziger Construktion so lange hemmend entgegentreten muss, als wir nicht Mittel besitzen, die objective Stärke und den Verlauf der erzeugten Ströme sicher und genau zu messen.

\title{
Beiträge zur Lehre vom Kreislauf der Kaltblüter.
}

Von

cand med. Franz Hofmeister aus Tübingen.

Mit 22 Holzschnitten.

Trotzdem schon bei einer erbeblichen Anzahl von Arbeiten, welche zur Untersuchung physiologischer und pathologischer Vorgänge am Kaltblüterherzen angestellt wurden, das Manometer als Registrirapparat diente, so war doch keine der bisher gewonnenen Curven geeignet, uns über die feineren Verhältnisse der pulsatorischen Blutdruckschwankung bei diesen Thieren Aufschluss zu geben. Ihre Begriindung findet diese Thatsache einmal in dem Umstand, dass die meisten Versuche am ausgeschnittenen oder wenigstens blossgelegten und künstlich durchströmten, oder auch blutleeren, jedenfalls also seiner normalen Arbeits- und namentlich Ernährungsbedingungen beraubten Herzen angestellt wurden.

Der zweite Grund liegt in der Unvollkommenheit der benützen manometrischen Vorrichtungen.

Die irrige Anschaung, dass es in erster Linie die Masse und schwere Beweglichkeit des Quecksilbers sei, welche das Bild der Pulscurve trübe, führte zur Anwendung eines Manometers, das mit Soda beziehungsweise Kochsalz $(0,7 \%)$ gefullt war. Allein eine Vergleichung der mit den beiden Apparaten gewonnenen 
Curven ${ }^{1}$ ) bestätigt auf den ersten Blick den von $H$ ưrthle ${ }^{2}$ ) ausgesprochenen Satz, ,dass die Ermittlung der Flitssigkeitsmenge, welche das Manometer zur Ausgleichung einer bestimmten Druckdifferenz erfordert, das wichtigste Kriterium für die Leistungsfähigkeit bezw. Trägheit des Apparates abgiebt." Demgemäss erleidet die Pulscurve des Kaltblüters durch das Sodamanometer dieselben Entstellungen, welche der genannte Forscher (l. c. p. 406) bei Anwendung des $\mathrm{Hg}$-manometers am Warmblïterpuls nachweist. Für die Wiedergabe des Kaltblüterpulses mittelst des Hg-manometers fällt der erwähnte Fehler ziemlich weg; denn in den relativ langen Zeiträumen, in denen sich die pulsatorischen Veränderungen des Blutdrucks bei diesen Thieren abspielen, vermag die zur Ausgleichung der entstehenden Druckdifferenzen nothwendige Flüssigkeitsmenge wobl aus der Arterie in das Manometer resp. aus diesem zurück in die Arterie zu treten. Wir erhalten somit ein ziemlich richtiges Bild von der Grösse der durch eine Herzcontraction im Arteriensystem erzeugten Drucksteigerung (s. Fig. 1). Dagegen tritt die Trägheit des Quecksilbers hindernd in den Weg, wenn es sich um die Darstellung feiner Einzelheiten handelt, indem minimale und rasch vorübergehende Druckschwankungen nicht genügen, die schwere Fluissigkeit in Bewegung zu setzen.

Fig. 1.

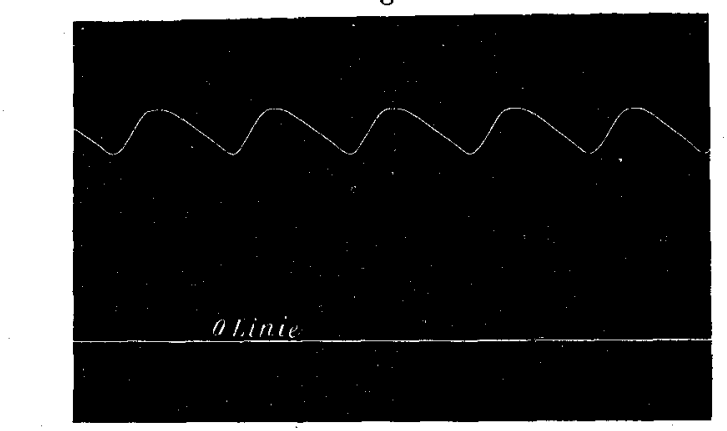

Blutdruckcurve der Aorta communis von Bufo terrestris mittelst des Hg-manometers verzeichnet.

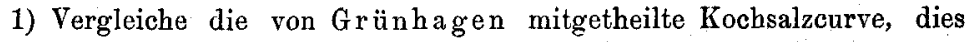
Archiv Bd. XXV p. 253 mit den von Gompertz veröffentlichten $\mathrm{Hg}$ - curven, Du Bois.Reymond's Arch. für Physiologie 1884 p. 257, sowie mit Fig. 1, welche eine $\mathrm{Hg}$ - curve der Aorta communis von Bufo terrestris darstellt.

2) Dies Arch. Bd. XLIII p. 408. 
Beide Uebelstände, grosse Flïssigkeitsverschiebung und Trägheit der Masse, hat $\mathrm{Hürthle} \mathrm{bei} \mathrm{seinen} \mathrm{Manometern} \mathrm{vermieden}$ und die Resultate, welche er mit seinen Apparaten an Warmbliitern erzielte, mussten dazu einladen, dieselben auch an Kaltblitern zu versuchen. Vornehmlich schien das Gummimanometer (dem auch Herr Professor Grutzner vor allen anderen derartigen Apparaten den Vorzug ertheilt), für meine Versuche geeignet, da in ihm die Flüssigkeitsverschiebung sehr klein zu machen ist und die Anwendung von verschieden dicken und verschieden stark gespannten Gummimembranen die Empfindlichkeit desselben innerbalb weiter Grenzen zu verändern, beziehungsweise dem betreffenden Fall leicht und bequem anzupassen gestattet.

So machte ich denn auf Anregung meines verehrten Lehrers, Herrn Professor Dr. Grützner, dem ich an dieser Stelle für das meiner Arbeit entgegengebrachte Interesse, sowie für die freundliche Unterstützung bei Ausführung derselben, meinen wärmsten Dank ausspreche, im verflossenen Sommersemester im Tubinger physiologischen Institut eine Reihe von Versuchen an Kröten und Schlangen, deren Resultate ich im Folgenden mittheile ${ }^{1}$ ).

\section{Methodische Vorbemerkungen.}

Einige kurze Notizen mögen dazu dienen, ein Bild der Versuchsmethode zu geben.

Die Kröten wurden auf einem Brettchen an den vier Extremitäten meist in Bauchlage festgebunden und ausserdem noch in halber Höhe des Kreuzbeins oder etwas tiefer durch beiderseits eingesetzte Haken festgehalten, um die oft sehr heftigen Bewegungen der muskelkräftigen Thiere möglichst zu beschränken und die Verbindungsstelle von Arterie und Canüle vor Zerrung zu schittzen. Für Schlangen konnte ich, da ein Anbinden ohne Behinderung der Athmung und der Circulation nicht möglich war, keine andere Befestigungsart finden, als dass ich sie mittelst feiner Nägel, welche je nach Bedürfniss in grösserer oder geringerer Entfernung durch aufgehobene Hautfalten gesteckt wurden, auf einem Lattenstick festnagelte.

1) Frösche wurden von der Untersuchung ausgeschlossen, da die Kleinheit der mir zur Verfügung stehenden Thiere und die grosse Zartheit ihrer Gefässe das Arbeiten mit ihnen undankbar erscheinen liess. 
Um Blutverluste möglichst zu vermeiden, wurden alle bei der Präparation im Wege liegenden Gefässe doppelt unterbunden und durchschnitten; auch wurde die Arterie vor Einführung der Cantile mit einer feinen Charrière-Pincette (deren Branchen zur Vermeidung von Verletzungen mit feuchten Wattepölsterchen bekleidet waren) zugeklemmt. So war von dieser Seite dafür gesorgt, dass das Herz seine normale Füllung beibehielt; andererseits wurde, um uberhaupt Schädlichkeiten von demselben fernzuhalten, der Ort der Einfuhrung stets möglichst weit nach der Peripherie zu gelegt. Bei Kröten führte ich die Canüle in der Regel in die Arteria cruralis ein: in einer Anzahl von Versuchen benützte ich die Aorta communis und in noch andern den einen Aortenbogen, um die Form der Pulse in versehiedener Entfernung vom Centrum studiren zu können. Bei Ringelnattern fand die Canüle stets in der Aorta abdominalis ca. $25-50 \mathrm{~cm}$ vom Herzen ibren Platz. Als Uebertragungsflüssigkeit diente eine $25 \%$ Lösung von Magnesiumsulfat.

Zur Zeitmarkirung benützte ich den von Griltzner ${ }^{1}$ ) angegebenen Tropfapparat, dessen Zuverlässigkeit durch zahlreiche Versuche sicher gestellt war. Die Zahl der fallenden Tropfen wurde auch stets während des Versuchs mehrmals durch Vergleichung mit der Secundenuhr controlirt.

Um alle äusseren störenden Einflüsse, soweit es in meiner Macht lag, zu beseitigen, experimentirte ich stets in einem nach Norden gelegenen Zimmer meist Vormittags, so dass die bei meinen Versuchen in Betracht kommenden Temperaturschwankungen sich in den engen Grenzen von $16-20^{\circ} \mathrm{C}$. bewegen, für die Beurtheilung der Resultate also unbeschadet der Genauigkeit ausser Acht gelassen werden können. Das Thier wurde stets so gelagert, dass das Herz sich mit dem Manometer in gleicher Höhe befand. Nach jedem Versucbe wurde das Manometer mittelst des von Hürthle (l. c. p. 421) angegebenen Calibrirmanometers graduirt, eine Vorsichtsmasssregel, die sich als unbedingt nothwendig erweist. Bezüglich der mitgetheilten Curven ist zu bemerken, dass die Fusspunkte, wo nicht plötzliche Schwankungen des Blutdrucks vorliegen, der Horizontalstellung des Schreibhebels entsprechen. Die Curven sind von links nach rechts zu lesen.

1) Dies Archiv Bd. XLI p. 290. 


\section{Theil.}

\section{Blutdruck und pulsatorische Schwankung unter normalen Verhältnissen.}

An den im vorigen Abschnitt angegebenen Stellen des arteriellen Systems untersuchte ich die normalen Blutdruckverhältnisse. Bei den Versuchen, welche die Untersuchung des Aortenpulses bezweckten, wurde meist rasch eine Cruraliscurve gezeichnet und dann nach Resection des Kreuzbeins die Canüle in die Aorta communis eingeführt. Wurde die Canüle in den Aortenbogen gesetzt, so musste in der Regel zum Zweck bequemerer Einführung das Sternum gespalten und ein Theil desselben sowie der Clavikel und des 0 s coracoideum entfernt werden.

Fig. 2 liefert Beispiele normaler Blutdruckeurven von Bufo terrestris und Tropidonotus natrix ${ }^{\mathbf{1}}$ ).

A entstammt dem linken Aortenbogen

B der Aorta abdominalis

C der Arteria cruralis sinistra einer Kröte.

D wurde von der Bauchaorta einer Ringelnatter gewonnen.

E zeigt die Carotiscurve eines Kaninchens (ich theile dieselbe hier mit, um eine bequeme Vergleichung der verschiedenen Raschheit der einzelnen Herzcontraction sowie der Frequenz der Pulse beim Warm- und Kaltbltter zu ermöglichen) (s. Fig. 2. S. 365).

Der allen Curven gemeinsame, schon bei blosser Betrachtung anffallende Typus ist folgender: Der Anstieg beginnt nahezu geradlinig, in seinem oberen Theil krümmt er sich allmählich der Abscisse zu; die Krlimmung geht auf der Höhe des Maximaldrucks (bei 2) oft ohne scharfe Grenze in eine horizontale oder kaum merklich absinkende Linie uber; das Ende dieser Linie (3) ist scharf markirt dureh einen plötzlich beginnenden jähen Abfall, der nach kurzer Dauer mit einer deutlich hervortretenden Knickung der Curve (4) einem langsamen Absinken auf die Anfangshöhe (1) Platz macht. Durch die vier an jeder Curve scharf hervortretenden Punkte ist der Einzelpuls in vier Abschnitte getheilt. Wir bezeichnen dieselben:

1) Solche Curven, welche die Form der Druckschwankung getreu wiedergeben sollen, müssen mit einem Minimum von Reibung gezeichnet sein. 
1-2 Anstieg,

2-3. Verharrung;

3-4 Steilabfall,

4-1 Allmählicher Abstieg.

In dem letzten Theil (zwischen 4 und 1) finden wir mitunter, namentlich bei niedrigem Drucke, eine weitere Abknickung der

Fig. 2.

Blatdruckcurven, $A-C$ von Bufo, $D$ von Tropidonotus. - A Arcus aortae, B Aorta communis, C Arteria cruralis. - D Aorta abdominalis. A, B, C stammen von 3 verschiedenen Thieren. E Carotiscurve vom Kaninchen (hier hatte die Membran viel grössere Anfangsspannung).

Curve, in dem Sinne, dass eine Concavität gegen die Abscisse entsteht. Figur 3 zeigt dieselbe (bei 5) sehr scharf ausgeprägt (s. Fig. 3). Häufig, aber durchaus nicht immer Fig. 3. bemerkt man am Ende des Abfalls bezw. zu Beginn des Anstiegs eine kurz dauernde flache Erhebung; in manchen Fällen tritt auch an ihrer Statt eine kleine horizontale oder etwas ansteigende Linie auf, wie sie z. B. in Fig. 3 bei $v$ leicht angedeutet ist.

E. PHäger, Archiv f. Physiologie, Ba, XLIV.

Curve vom Arcus aortae v. Bufo bei gesunkenem Blutdruck. 
Fig. 4 zeigt die Erhebung zu Beginn des Anstiegs deutlich (die ubrigen Curvenabschnitte sind weniger scharf ausgeprägt), ebenso Fig. 8 II (s. Fig. 4 bei v).

Blutdruckeurve von der Ringelnatter.

Die beträchtlichen Unterschiede, welche durch genaue Messung $\left.{ }^{1}\right)$ der einzelnen Abschnitte zwischen den an den drei erwähnten Stellen erhaltenen Curven sich ergaben, fordern zu specieller Behandlung auf.

Neben der Druckabnahme machen sich nämlich auch in der Form der Pulswelle beim Fortschreiten vom Centrum nach der Peripherie bestimmte stets wiederkehrende Veränderungen geltend, die theils in verschiedener Daner, theils in verschiedener Höhe bezw. Tiefe oder Steilheit der einzelnen Pbasen ihren Ausdruck finden. Wir werden uns in einem der folgenden Abschnitte eingehend mit diesen Verhältnissen zu beschäftigen haben.

\section{Frequenz, Grösse des Blutdrucks und der pulsato- rischen Schwankung. Mitteldruck.}

A. Bufo terrestris.

Eine grosse Menge von Zählungen ergab für die Pulsfrequenz die Mittelzahl von 48 Schlägen in der Minute; doch kamen Abweichungen bis zu 10 und 15 Schlägen nach oben oder unten so häufig vor, dass wir sie wohl als noch in den normalen Grenzen liegend bezeichnen miissen.

1) Die zu Messungszwecken bestimmten Curven wurden auf rasch rotirender $(2,5-4 \mathrm{~cm}$ in der Secunde) Trommel aufgezeichnet. Eine Zeitmarkirung mit schwingénder Stimmgabel hielt ich bei der Genauigkeit des Tropfapparats und dem sehr gleichmässigen Gang des verwendeten Kymographions für überflüssig. Zu den Messungen wurde ein mit Nonius versehener Millimetermaassstab benutzt. 
Bezüglich der für den Blutdruck gefundenen Werthe ist zu beriicksichtigen, dass in Wirklichkeit nicht der in der benitzten Arterie, sondern der an der nächst höheren Theilungsstelle herrschende Seitendruck gemessen wurde.

Wenn ich bei Besprechung der Grösse des Blutdrucks die in der Arteria cruralis bestehenden Verhältnisse zum Ausgangspunkt nehme, so hat dies seinen Grund in der Fuille der gerade von dieser Arterie gesammelten Beobachtungen, welche eine Aufstellung möglichst allgemein giultiger Mittelwerthe gestattet.

Da ich eine Beziehung der Blutdrucksgrösse zum Körpergewicht von vorne herein nicht für unwahrscheinlich hielt, wurde jedes Thier vor dem Versuch gewogen. Die Zusammenstellung einer grossen Zahl von Versuchen ergab für die Arteria cruralis bei einem Durchschnittsgewicht der Thiere von $116 \mathrm{gr}$ den Minimaldruck zu $41 \mathrm{~mm} \mathrm{Hg}$, den Maximaldruck zu $52 \mathrm{~mm} \mathrm{Hg.} \mathrm{Die}$ pulsatorische Schwankung beträgt demnach $11 \mathrm{~mm} \mathrm{Hg}$ und entspricht $27 \%$ des Minimaldrucks.

Zur Feststellung des Mitteldrucks wurden einzelne Pulse genan vergrössert auf Millimeterpapier gezeichnet und durch Auszählung der Quadrate der gesuchte Werth gefunden. Es zeigte sich hierbei, dass derselbe bei allen normalen Pulsen ziemlich genau mit dem ersten Drittel der Druckdifferenz zusammenfiel. Hiernach finden wir fuir den Mitteldruck in der Arteria cruralis den Werth von $44-45 \mathrm{~mm} \mathrm{Hg}$. Dass die Schwankungen um diesen Mittelwerth (ebenso wie bei der Frequenz) sehr bedeutend sein können, ist selbstverständlich.

Das factische Bestehen des vermutheten Zusammenhangs zwischen Blutdruck und Körpergewicht beweist die folgende Zusammenstellung:

\begin{tabular}{|c|c|c|c|c|}
\hline $\begin{array}{l}\text { Versuchs- } \\
\text { Nummer }\end{array}$ & $\begin{array}{l}\text { Gewicht } \\
\text { in } \mathrm{gr}\end{array}$ & $\left\{\begin{array}{c}\text { Druck } \\
\text { schwankung } \\
\text { in mm Hg }\end{array}\right.$ & $\begin{array}{l}\text { Mittel- } \\
\text { druck in } \\
\text { mm Hg }\end{array}$ & 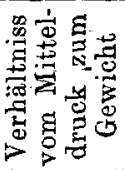 \\
\hline XXVII & 95 & $37-50$ & 41 & 0,43 \\
\hline VII & 103 & $39-50$ & 43 & 0,42 \\
\hline XXIII & 110 & $43-52$ & 46 & 0,42 \\
\hline $\mathrm{XXV}$ & 128 & $43-58$ & 48 & 0,38 \\
\hline VIII & 133 & $48-60$ & 52 & 0,39 \\
\hline XXI & 145 & $59-71$ & 63 & 0,43 \\
\hline
\end{tabular}


Wir sehen also mit zunehmendem Körpergewicht den Blutdruck steigen. Das Verhältniss des letzteren zum ersteren stellt sich, wie aus vorstehender Tabelle ersichtlich, so, dass sich der Blutdruck (gemessen in der Arteria cruralis, ausgedriickt in $\mathbf{m m ~ H g}$ ) zum Gewicht des Thiers (ausgedrïckt in Grammen) verhält ungefähr wie $4: 10$. Jahreszeit, Dauer der Gefangenschaft, Ernährungszustand des Thieres werden auf das Verhältniss zweifellos von Einfluss sein. Bei Anlegung obiger Tabelle konnten natürlich nur solche Versuche Verwendung finden, bei denen frisch oder erst wenige Tage gefangene Thiere zur Verfügung standen, die ohne einen Tropfen Blutverlust an's Manometer gebracht wurden.

In dieser Abhängigkeit des Blutdrucks vom Körpergewicht liegt die Ursache dafür, dass es mir nicht möglich war, eine vollkommen reine Vergleichung der an den verschiedenen Stellen des arteriellen Systems herrschenden Drucke anzustellen, da ich zu der Zeit, als ich meine Versuche an der Aorta communis und besonders am Aortenbogen anstellte, leider nur Thiere bekommen konnte, die fast sämmtlich an Gewicht hinter den früher benutzten zuriickblieben.

Ich erhielt somit für die Aorta viel kleinere Werthe, als man nach den Befunden an der Arteria cruralis hätte erwarten sollen. Um zur Vergleichung geeignete Werthe zu erhalten, liess ich von den Cruralisversuchen diejenigen ausser Betracht, bei denen besonders schwere Thiere zur Verwendung gekommen waren, und erhielt dann als Mittel aus 5 Versuchen folgendes Resultat.

Bufo terrestris, Arteria cruralis:

\begin{tabular}{c|c|c|c|c|c}
\hline Mittel aus & $\begin{array}{c}\text { Gewicht } \\
\text { in gr }\end{array}$ & $\begin{array}{c}\text { Druck- } \\
\text { schwankung } \\
\text { in mm Hg }\end{array}$ & $\begin{array}{c}\text { Mittel- } \\
\text { druck in } \\
\text { mm Hg }\end{array}$ & $\begin{array}{c}\text { Verhältniss } \\
\text { von Mittel- } \\
\text { druck zum } \\
\text { Gewicht }\end{array}$ & $\begin{array}{c}\text { Pulsgrösse } \\
\text { in \% des } \\
\text { Minimal- } \\
\text { drucks }\end{array}$ \\
\cline { 2 - 7 } & $\mathbf{1 0 4}$ & $38-49$ & 42 & 0,4 & 29
\end{tabular}

Versuche an der Aorta abdominalis ergaben:

\begin{tabular}{|c|c|c|c|c|c|}
\hline \multirow[t]{2}{*}{$\begin{array}{l}\text { Mittel aus } \\
3 \text { Versuchen }\end{array}$} & $\begin{array}{l}\text { Gewicht } \\
\text { in } \mathrm{gr}\end{array}$ & $\begin{array}{c}\text { Druck- } \\
\text { schwankung } \\
\text { in } \mathrm{mm} \mathrm{Hg}\end{array}$ & Mittel- & $\begin{array}{c}\text { Verhältniss } \\
\text { von Mittel- } \\
\text { druck zum } \\
\text { Gewicht }\end{array}$ & $\begin{array}{c}\text { Pulsgrösse } \\
\text { in } \% \text { des } \\
\text { Minimal- } \\
\text { drucks }\end{array}$ \\
\hline & 103 & $39-53$ & 44 & 0,43 & 36 \\
\hline
\end{tabular}


Solche am Arcus aortae sinister:

\begin{tabular}{c|c|c|c|c|c}
\hline Mittel aus & $\begin{array}{c}\text { Gewicht } \\
\text { in gr }\end{array}$ & $\begin{array}{c}\text { Druck- } \\
\text { schwankung } \\
\text { in } \mathrm{mm} \mathrm{Hg}\end{array}$ & $\begin{array}{c}\text { Mittel- } \\
\text { druck in } \\
\mathrm{mm} \mathrm{Hg}\end{array}$ & $\begin{array}{c}\text { Verhältniss } \\
\text { von Mittel- } \\
\text { druck zum } \\
\text { Gewicht }\end{array}$ & $\begin{array}{c}\text { Pulsgrösse } \\
\text { in \% } \% \text { des } \\
\text { Minimal- } \\
\text { drucks }\end{array}$ \\
\hline 7 Versuchen & 77 & $40-56$ & 45 & 0,58 & 40
\end{tabular}

Nach dieser Tabelle würden wir für Thiere von ca. $100 \mathrm{gr}$ Gewicht einen Mitteldruck an der Theilungsstelle des Bulbus arteriosus von ungefähr $58 \mathrm{~mm} \mathrm{Hg}$ berechnen. - Wenn uns nun die gegebenen Zahlen auch keine absolute Vergleichung erlauben, so können wir nichts desto weniger die charakteristischen Veränderungen, welche der Blutdruck mit zunehmender Entfernung vom Herzen erleidet, aus ihnen herauslesen und sie kurz in folgenden Sätzen zusammenfassen:

1) Der Mitteldruck nimmt nach der Peripherie zu s tetig ab (das Verbältniss der Abnahme anzugeben ist auf Grund des Gesagten leider nicht möglich).

2) Der Betrag der pulsatorischen Schwankung wird kleiner und zwar sowohl absolut als auch im Verhältniss zum Minimaldruck. Dies wird bewirkt dadurch, dass:

3) Der Maximaldruck in rascherem Verhältniss abnimmt als der Minimaldruek.

Auf die Erklärung dieser Thatsachen komme ich später zur'ick.

\section{B. Tropidonotus natrix.}

Bei diesen Thieren fand ich als Mittel aus 6 Versuchen (in denen die Präparation ganz ohne Blutverlust gelungen war), folgende Werthe:

\begin{tabular}{c|c|c|c|c}
\hline Mittel aus & $\begin{array}{c}\text { Pulszahl } \\
\text { in der } \\
\text { Minute }\end{array}$ & $\begin{array}{c}\text { Druck- } \\
\text { schwankung } \\
\text { in mm Hg }\end{array}$ & $\begin{array}{c}\text { Mittel- } \\
\text { druck in } \\
\text { mm Hg }\end{array}$ & $\begin{array}{c}\text { Pulsgrösse } \\
\text { in \% } \% \text { des } \\
\text { Minimal- } \\
\text { drucks }\end{array}$ \\
\hline 60 & $83-95$ & 87 & $14-15$
\end{tabular}

Die im Verhältniss zum Mitteldruck auffallende Kleinheit der pulsatorischen Schwankung erklärt sich wohl am einfachsten aus 
der bedeutenden Entfernung der Canüle vom Herzen. Beziehungen zwischen Blutdruck und Körpergewicht konnten nicht festgestellt werden, da die Versuchsthiere grösstentheils gravid waren. Ebenso konnte ich die Untersuchung über Veränderung der Curve durch die verschiedene Entfernung vom Herzen nicht auf diese Thiere ausdehnen.

Den von Ludwig und Luchsinger ${ }^{1}$ ) und anderen behaupteten Parallelismus zwischen Druck- und Frequenzänderung konnte ich nicht nachweisen. Es finden sich allerdings auch in meinen Versuchen zahlreiche Beispiele, welche für die Anschauung der genannten Forscher verwerthbar wären. Allein diesen stehen auch eine grosse Zabl von Fällen gegenüber, in denen Druckänderung von gar keiner oder von entgegengesetzter Frequenzänderung begleitet war. Jedenfalls wage ich auf Grund meiner Versuchsergebnisse nicht, mich für oder wider zu entscheiden; sicher werden ja die Verhältnisse beim lebenden Thier wesentlich complicirt durch nervöse Einfliisse, welche bei den Untersuchungen jener Forscher, die am ausgeschnittenen Herzen arbeiteten, ausgeschlossen waren ${ }^{2}$ ).

Formverschiedenheiten der Pulse des Aortenbogens, der Aorta abdominalis und der Arteria cruralis.

1) Der Anstieg hat die kürzeste Dauer bei den Pulsen der Aorta communis, die längste bei der Arteria cruralis. Der Arcus

1) Dies Archiv Bd. XXV p. 227.

2) Des öfteren beobachtete ich bei Kröten und Schlangen kurze Zeit (1/2-2 Minuten) nachdem das Thier an's Manometer gebracht war, eine spontane Aenderung des Blutdrucks und zwar (mit Ausnahme eines einzigen Falls) stets eine Senkung. Spontan nenne ich sie desshalb, weil sie stets ohne jede Veränderung der äusseren Versuchsbedingungen erfolgte und mir eine Ursache für dieselbe bis jetzt unerfindlich ist. Zuweilen sank der Mitteldruck um 8-9 $\mathrm{mm} \mathrm{Hg}$; damit war fast in allen Fällen eine Frequenzabnahme, die bis zu 8 Schlägen pro Minute betragen konnte, verbunden. Die einzige allerdings etwas gesuchte Deutung, welche ich dieser Erscheinung etwa geben könnte, ginge dahin, dass durch die mit der Präparation verbundene sensible Reizung eine lang nachwirkende reflectorische Erregung gesetzt würde, welche in der nach Verbindung der Arterie mit dem Manometer eintretenden Ruhepause wieder zum Verschwinden käme. Doch berubt dieser Erklärungsversuch durchaus nur auf Vermuthung. 
aortae steht bezüglich der Anstiegszeit in der Mitte. Die Steilheit, gemessen durch das Verhältniss der Drucksteigerung (Ordinate) zu der Zeit, in der sie sich vollzieht (Abscisse), nimmt zu, je näher wir dem Herzen kommen; doch gilt dieser Satz unbedingt nur für Cruralis und Abdominalaorta. Soll er allgemeine Giltigkeit haben, so dürfen wir aus später darzulegenden Gründen nur die untern zwei Drittel der Erhebung in Betracht ziehen.'

2) Die Verharrung auf der Höhe des Maximaldrucks ist im Arcus aortae kürzer als in der Aorta communis und Arteria cruralis; die Unterschiede zwischen letzteren beiden sind, wenn vorbanden, so unbedeutend, dass sie sich der Messung entziehen. So wird die Summe von Anstieg und Verharrung im Arcus und in der Bauchaorta ungefähr gleich, bleibt aber kleiner als in der Arteria cruralis.

3) Der kurze Steilabfall ist an allen drei Stellen ungefähr von gleicher Dauer. Bezuiglich seiner Steilheit und absoluten Tiefe verhält er sich analog dem Anfangstheil des Anstiegs, d. h. dieselben sind in der Nähe des Centrums am grössten.

4) Die Dauer des Gesammtabfalls (= Steilabfall + allmählicher Abstieg) ist im Arcus und der Aorta communis ungefähr gleich, in der Arteria cruralis (entsprechend der längeren Dauer von Anstieg + Verharrung) etwas kürzer.

Die erwähnte Abknickung im letzten Theil des absteigenden Schenkels (Concavität gegen die Abscisse) findet sich bei allen drei Pulsarten zuweilen, ebenso die kleine Erhebung vor Beginn des eigentlichen Anstiegs.

Um ein übersichtliches Bild der beschriebenen Differenzen zu geben, lasse ich eine Zusammenstellung der für die einzelnen Curventheile gefundenen Mittelwerthe, sowie eine an der Hand derselben entworfene schetnatische Zeichnung der den drei verschiedenen Gefässen entstammenden Pulscurven folgen (s. Fig 5 und Tab. anf S. 372).

\section{Erklärung der Pulsform.}

a) Ansteigender Schenkel.

Die allmähliche Verlangsamung des Anstiegs, welche man aus der Form desselben unmittelbar erkennen kann, wird durch verschiedene Momente bedingt.

Erstens nimmt wohl gegen das Ende der Ventrikelcontraction die austreibende Kraft des Ventrikels allmählich ab, entsprechend den 
immer geringeren Kraftleistungen eines Muskels, die er mit zunehmender Contraction entfaltet. Die Einströmungsgeschwindigkeit des Blutes in die Arterien nimmt also ab. Zweitens wird mit steigendeon

Fig. 5.

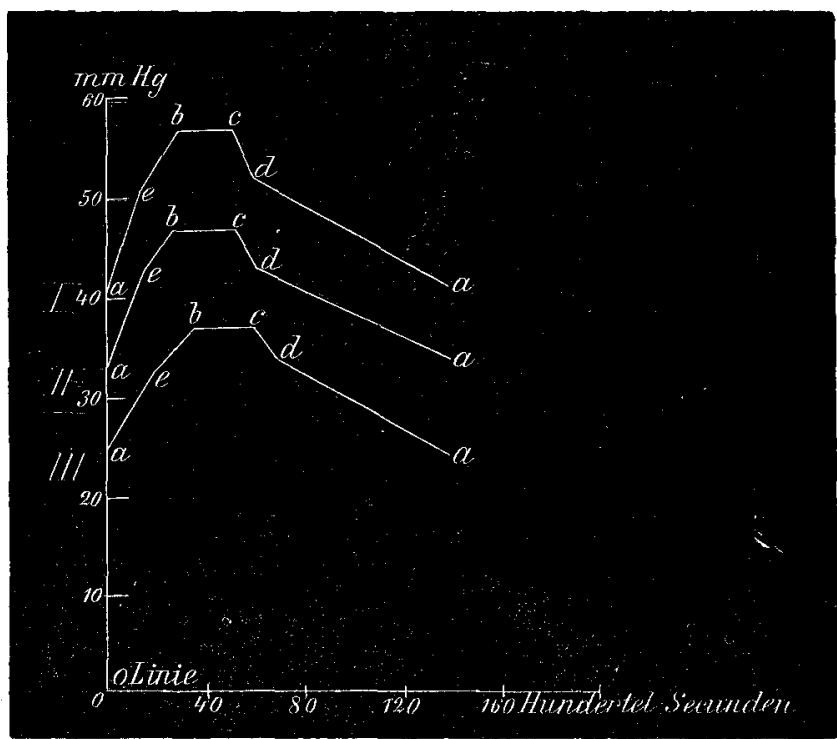

Vergleichendes Schema der Pulswelle I im Arcus aortae, II in der Aorta communis, III in der Arteria cruralis sinistra.

\begin{tabular}{|c|c|c|c|c|c|c|c|c|c|c|}
\hline \multirow{2}{*}{ Gefäss } & \multirow{2}{*}{ 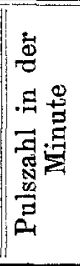 } & \multicolumn{2}{|c|}{$\begin{array}{l}\text { Drucksteige- } \\
\text { rumg pro } \\
1 / 10 \text { Sec. in } \\
\text { mm Hg }\end{array}$} & \multicolumn{2}{|c|}{$\begin{array}{l}\text { Druckab- } \\
\text { nahme durch } \\
\text { den Steilab- } \\
\text { fall in mm Hg }\end{array}$} & \multicolumn{5}{|c|}{$\begin{array}{c}\text { Dauer der einzelnen } \\
\text { Phasen ausgedrückt in } \\
1 / 100 \text { Secunden }\end{array}$} \\
\hline & & $\mid \begin{array}{c}\text { für den } \\
\text { ganzen } \\
\text { Anstieg } \\
(\mathbf{a}-\mathbf{b})\end{array}$ & $\begin{array}{c}\text { für die } \\
\text { untern } \\
2 / 3 \text { des } \\
\text { An- } \\
\text { stiegs } \\
(a-e) \\
\end{array}$ & absolut & $\begin{array}{c}\text { auf } 1 / 10 \\
\text { Sec. } \\
\text { berech- } \\
\text { net }\end{array}$ & 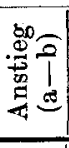 & 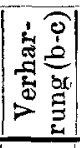 & 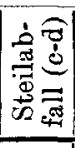 & 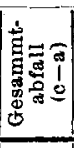 & 焉 \\
\hline $\begin{array}{l}\text { Arcus aortae } \\
\text { sinister }\end{array}$ & 43 & 5,0 & 6,5 & 4,4 & ca. $6 \|$ & 32 & 20 & $7-8$ & 89 & 141 \\
\hline $\begin{array}{l}\text { Aorta com- } \\
\text { munis }\end{array}$ & 41 & 5,0 & 5,3 & 4,0 & ca. 5 & 28 & 26 & $7-8 \mid$ & 92 & 146 \\
\hline $\begin{array}{l}\text { Arteria cruralis } \\
\text { sinistra }\end{array}$ & 43 & 3,6 & 4,3 & 3,0 & ca. 4 & 36 & 26 & $7-8$ & 77 & 139 \\
\hline
\end{tabular}

Druck in der Aortenwurzel der Abfluss nach den Venen zweifellos rascher; das Verbältniss des letzteren zum ersteren steigt also fortwährend. Die Folge muss eine Verlangsamung der Druckerhöhung 
sein. Schliesslich kommen wir an einen Punkt, wo Einstrom und Abfluss sich die Wage halten; es wird also keine Drucksteigerung mehr erfolgen. Damit bört aber auch der Abfluss auf, schneller zu werden, und das Resultat ist ein Verharren auf der erreichten Höhe. Diese Factoren bringen an allen drei untersuchten Stellen die als typisch bezeichnete Form des Anstiegs zu Stande.

Worin liegt nun der Grund der im letzten Capitel beschriebenen Verschiedenheiten? Verschiedene Forscher (wie Weber, Marey u. a.) haben nachgewiesen, dass die Elasticität der Gefăsswände den intermittirenden Herzaortenstrom in einen remittirenden und schliesslich continuirlichen verwandelt. Durch diese Wirkung der elastischen Kräfte verliert der Anstieg an Steilheit und Höbe und nimmt an Dauer zu; andererseits wird die untere Grenze des Drucks höher gerïckt. Diese Wirkung wird aber um so mehr zu Tage treten, je mehr elastische Factoren in die Leitung eingeschaltet sind. Je weiter wir uns im Gefässsystem vom Herzen entfernen, um so grösser wird die absolute Menge der elastischen Elemente; wir dürfen also von vornberein erwarten, dass mit dem Fortschreiten der Welle nach der Peripherie die Steilheit des Anstiegs abnimmt, seine zeitliche Dauer zunimmt. Wie wir aber gesehen, bestätigt sich diese Erwartung nur zum Theil, nur für den Anfang der Drucksteigerung. Gerade der Arcus aortae, bei dem wir doch den steilsten und zeitlich klirzesten Anstieg voraussetzen müssten, macht eine Ausnabme; wir finden denselben im Gegentheil länger dauernd und nicht steiler als in der Bauchaorta. (S. Tabelle auf S. 372 und Fig. 5.) Betrachten wir genau die Bedingungen, unter welchen die gedachten Curven zu Stande kommen, so dürfte die Erklärung jenes ausnahmsweisen Verhaltens sich ziemlich einfach gestalten. Durch Einbindung der Cantile in den Arcus aortae ist dieser verschlossen. Der Querschnitt der Leitung, durch welchen die vom Herzen ausgeworfene Flüssigkeitsmenge ihren Abfluss nehmen muss, ist dadurch bedeutend verkleinert, der Abfluss also wesentlich gehemmt; demzufolge wird sein Verhältniss zum Einstrom langsamer wachsen, als bei vollständig offener Leitung. Die Folge ist eine Verlängerung der Drucksteigerung ( $a-b$ Fig. 5 I). Diese Verlängerung wird sich aber weniger bemerklich machen im Anfangstheil des Anstiegs (a-e), wo der Einstrom ohnehin den Abfluss bedeutend iberwiegt; sie wird vielmehr hauptsächlich zur Geltung kommen im letzten Theil, in 
welchem Einstrom und Abfluss sich allmählich gleich werden; wir kommen also im wesentlichen auf eine Verlängerung des weniger steilen Endes $(e-b)$ des Anstiegs. Da die Dauer des ganzen Einstroms $(a-c)$ keine Aenderung erleidet, wird jene Verlängerung der Druckerböhung auf Kosten der Verharrungsdauer $(b-c)$ zu Stande kommen müssen. Dass dies Verhältuiss thatsächlich vorhanden ist, haben wir gesehen. Neben der Verlängerung des weniger steilen Theils bewirkt der gehemmte Abfluss wohl auch noch eine Beschleunigung der Drucksteigerung im Beginn des Anstiegs - wenigstens lässt der im Arcus aortae für die untern zwei Drittel $(\mathbf{a}-\mathbf{e})$ gefundene Werth von $6,5 \mathrm{~mm} \mathrm{Hg}$ pro $1 / 10$ Secunde dies vermuthen. - Doch ist diese letztere nicht bedeutend genug, um die Wirkung der ersteren (Verlängerung) auf das Verhältniss von Ordinate zu Abscisse völlig zu compensiren.

Noch augenfälliger wird die beschriebene zeitliche Verschiebung (des Verhältnisses von $a b: b c$ ), wenn wir durch Verschluss des (gleichseitigen) Ductus pulmocutaneus den Querschnitt der Abflussöffnung noch mehr reduciren. Doch wird bei dieser starken Behinderung des Abflusses die Drucksteigerung so erheblich beschleunigt, dass eine Uebercompensation der Anstiegsverlängerung eintritt (dass also der Anstieg nicht bloss zeitlich verlängert, sondern auch steiler wird, als vorher). Die folgenden Zahlen mögen zur Erläuterung des Gesagten dienen.

\begin{tabular}{|c|c|c|c|}
\hline \multirow{2}{*}{\multicolumn{2}{|c|}{$\begin{array}{c}\text { Versuch XXIX } \\
\text { Bufo } \\
\text { terrestris }\end{array}$}} & \multicolumn{2}{|c|}{$\begin{array}{l}\text { Canüle im Arcus } \\
\text { aortae sinister }\end{array}$} \\
\hline & & $\begin{array}{c}\text { ohne } \\
\text { Eingriff }\end{array}$ & $\begin{array}{c}\text { Ductus pulmo- } \\
\text { cutaneus } \\
\text { sinister com- } \\
\text { primirt }\end{array}$ \\
\hline \multicolumn{2}{|c|}{$\begin{array}{l}\text { Drucksteigerung *) } \\
\text { pro } 1 / 10 \text { Secunde } \\
\text { in } \mathrm{mm} \mathrm{Hg}\end{array}$} & 5,5 & 6,2 \\
\hline 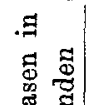 & $\begin{array}{c}\text { Anstieg } \\
(\mathrm{a}-\mathrm{b})\end{array}$ & 33 & 40 \\
\hline 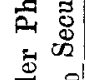 & $\begin{array}{l}\text { Verharrung } \\
\quad(b-c)\end{array}$ & 20 & 13 \\
\hline 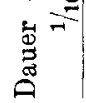 & $\begin{array}{l}\text { Summe } \\
(a-c)\end{array}$ & 53 & 53 \\
\hline
\end{tabular}

*) Mit Berücksichtigung des ganzen Anstiegs $(a-b)$. 
Durch dies Versuchsergebniss, welches ich wiederholt erzielte, glaube ich den Beweis für die Richtigkeit der obigen Erklärung erbracht $z u$ baben.

- An dieser Stelle sei auch die früher schuldig gebliebene Begründung für das raschere Sinken der Gipfelpunkte in Verhältniss zu dem der Fusspunkte nachgeholt. Wie erwähnt, äussert sich eine Wirkung der elastischen Leitung in dem Streben der beiden Extremlagen der Curve, sich einer Mittellage zu nähern; es kommt also zu einer Depression des Maximaldrucks und zu einer Erhöhung des Minimaldrucks. Somit geht die durch Vermehrung der elastischen Elemente der Blutbahn verursachte Verschiebung der Gipfelpunkte dem sinkenden Allgemeindruck gleich-, die der Fusspunkte entgegengesetzt gerichtet. Daher das langsamere Sinken der letzteren.

b) Absteigender Schenkel.

Konnten wir bisher ein nähseres Eingehen auf die Herabewegung umgehen - die Druckerhöhnng kann ja doch nur mit der Systole des Ventrikels einhergehen - so bietet sich uns jetzt, ehe wir zur Erklärung des zweiten Theils der Curve, des Abstiegs schreiten, die Nothwendigkeit, klarzulegen, in wie weit uns die manometrische Curve ein Bild von den Thätigkeitszuständen des Herzens giebt, ob und in wie weit die Phasen der Pulscurve mit denen einer Herzrevolution sich decken.

Bei einer Vergleichung des von $\mathrm{Cowl}$ und $\mathrm{Gad}^{1}{ }^{1}$ ) vor kurzem mitgetheilten Cardiogramms vom Frosch ${ }^{2}$ ) mit meinen Curven wurde ich auf die Thatsache aufmerksam, dass der ansteigende Theil der manometrischen Curve (= Anstieg + Verharrung, a--c in Fig. 5) in seiner Dauer nicht dem von jenen Forschern als Systole angesprochenen Curvenabschnitt gleichkam; während nämlich der letztere (a-d in Fig. 7) mehr als die Hälfte der Dauer einer Herzperiode einnahm, blieb der Betrag von Anstieg + Verharrung in meinen Versuchen bei allen normalen Pulsen unter $40 \%$ der ganzen Wellenlänge. Das Manometer schien demnach

1) Centralblatt f. Physiologie 1888 Nr. 11 p. 265.

2) Da eine so grosse Aehnlichkeit in der Pulscurve von Kröten und Schlangen besteht, schien mir eine Vergleichung von Frosuh- und Krötencurven vollends unbedenklich. 
das zeitliche Verhältniss der beiden Phasen der Herzaction nicht wiederzugeben. Die direkte Beobachtung des Herzens sollte hier Klarheit schaffen; ich legte desshalb bei dem nächsten Versuche, den ich am Aortenbogen anstellte (hier in der Nähe des Herzens konnte ich noch am ehesten erwarten, die Phasen der Herzaction in der Druckcurve ausgeprägt zu finden), das Herz bloss, obne den Herzbeutel zu verletzen. Es zeigte sich nun in der That, dass die Systole des Ventrikels die Diastole an Dauer bei weitem übertraf; dass also zu einer Zeit, wo der Schreibhebel des Manometers schon den absteigenden Schenkel der Pulscurve zeichnet, das Herz noch lange in Contraction verharrt. Um einen genaueren Einblick in diese Verhältnisse zu ermöglichen, markirte Herr Professor Gr ützner möglichst genau die direct beobachtete Herzbewegung durch Druck mit der Fingerspitze auf eine Marey'sche Trommel, die durch einen Schlauch mit einer Zeichentrommel in Verbindung stand, während das Manometer gleichzeitig die Pulscurve registrirte. Controlversuche betreffs der Genauigkeit dieser Methode anzustellen, erlaubte mir die Zeit nicht; doch glaube ich, dass sie, wenn auch mit Fehlern behaftet ${ }^{1}$ ), um so mehr Vertrauen verdient, als die in Betracht kommenden Zeiten viel grösser sind, als die etwaigen Fehler ${ }^{2}$ ). Die Auswerthung der so gewonnenen Curven ${ }^{3}$ ), von denen

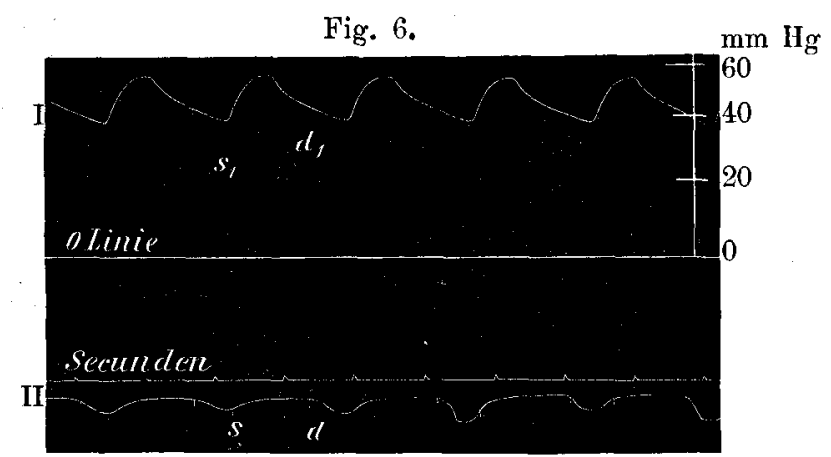

I Druckcurve aus dem Arcus aortae sinister von Bufo terrestris. II Markirung der Herzbewegung desselben Thiers. $s=$ Beginn der Systole, $d=B$ ginn der Diastole. $s$ ist mit $s_{1}$, $d$ mit $d_{1}$ isochron.

1) S. Kräpelin, deutsche med. Wochenschrift 1888 Nr. 33 S. 669.

2) Siehe auch Martius, Zeitschrift für klin. Med. Bd. XXII H. 3-6.

3) Die zu Messungen bestimmten Curven wurden auch hier bei raschem Trommelgang gezeichnet; die Bestimmung der isochronen Puncte geschah in bekannter Art. 
Fig. 6 ein Beispiel giebt, ergab die Zeit vom Beginn der Systole bis zu dem des Aorteneinstroms, also bis zur Oeffnung der Semilunarklappen (Martius'sche „Verschlusszeit", Cowl-Gad'sche „Anspannungzeit“) zu 0,1 Secunde. Die Systole betrug ungefähr $70 \%$ der ganzen Wellenlänge. Die bei allen Curven sich zeigende Uebereinstimmung veranlasste mich, zum Zwecke der genaueren Vergleichung in dem $\mathrm{C}_{0}$ wl-Gad'schen Cardiogramm die Lage der einzelnen hervortretenden Punkte, im Verhältniss zur Dauer der ganzen Herzperiode zu bestimmen. Zum besseren Verständniss des Folgenden theile ich hier die von jenen Forschern für die einzelnen Theile ihrer Curve eingefiuhrten Bezeichnungen mit (die Buchstaben beziehen sich auf Fig. 7 II und sind ebenfalls der angeführten Arbeit entnommen):

Fig. 7.

I Puls des Aortenbogens, II Schematisirtes (und vergrössertes)

Cardiogramm nach $\mathrm{Cowl}$ und $\mathrm{Gad}$.

a bis $b=$ Anspannungszeit des Ventrikels;

b,$\quad \mathrm{c}=$ Austreibungszeit des Ventrikels,

c, $\mathrm{d}=$ Systolische Verharrungszeit des Ventrikels,

$\mathrm{d}, \mathrm{e}==$ Entspannungszeit des Ventrikels,

$\mathrm{e}, \mathrm{f}=$ Anfüllungszeit des Ventrikels,

f,$\quad a=$ Diastolische Verharrungszeit des Ventrikels.

Bei der Berechnung. fand ich die Systole (a-d) zu 61\%; die Summe dieser und der Entspannungszeit (a-e) zu $74 \%$. Die letztere war also bei der Markirung noch zum grössern Theil in die Systole mit einbezogen, wahrscheinlich weil dem beobachtenden Auge der erste Beginn der Erschlaffung noch nicht als solche imponirt. - Da ich im Gegensatz zu der von verschiedenen Au- 
toren (Landois, Donders, Martius) am Menschen gemachten Beobachtung, dass Frequenzänderungen wesentlich durch Aenderung der Herzpause bezw. der Diastole zu Stande kommen, selbst bei erheblichen Differenzen in der Pulszahl das Verbältniss der markirten Systole zur ganzen Welle constant fand ${ }^{1}$ ), da ferner Cowl und Gad das mitgetheilte Cardiogramm als unter einem Optimum von Bedingungen gewonnen bezeichnen, so trug ich kein Bedenken, dasselbe der von mir als Mittel (für den Aortenbogen) berechneten Pulswelle zeitlich gleicbzusetzen und die Länge der einzelnen Abschnitte dementsprechend umzurechnen. Fig. 7 entstand anf diese Weise. Die Curve I entspricht dem in Fig. 5 I gegebenen Schema des Aortenbogenpulses (mit dem Unterschiede, dass hier ein Millimeter der Abscisse $=0,02$ Secunden ist, wäbrend er in Fig. 5 0,04 Secunden entspricht); die Curve II stellt das reducirte Cowl-Gad'sche Cardiogramm (ebenfalls schematisch) dar. Den Ausgangspunkt für die Berechnung bildete der in beiden Curven sicher identische Punkt $b$, der Anfang des Aorteneinstroms. Wir sehen anch hier, dass die Systole des Herzens $(a-d)$ nicht allein den Anstieg und die Verharrung, sondern auch noch den Steilabfall und einen Theil des allmählichen Abstiegs der Pulscurve in sich begreift. Ausserdem finden wir, dass das Ende des von Cowl und $\mathrm{G}$ a d als Austreibungszeit bezeichneten Curvenstuicks ziemlich genau mit dem Ende unserer Verharrung (s. Fig. 5) zusammenfällt; in dieser Thatsache erblicke ich einen wesentlichen Hait für die Annahme, dass die Vergleichung der beiden Curven, die ich anstellte, wirklich zulässig ist. - Dass in meinen Curven das Ende der Verharrung dem Aufhören des Aorteneinstroms entspricht, kann kaum zweifelhaft erscheinen; denn der eminent plötzliche Beginn des Absturzes kann doch wohl nur mit dem Verschwinden des drucksteigernden Factors in Zusammenhang gebracht werden.

Die bedeutende Steilheit des nun folgenden kurzen Abfalls (c-d in Fig. 5), ebenso wie seine scharfe Begrenzung nach unten sprechen entschieden gegen ein Hervorgehen desselben aus blossem, starkem Abfluss nach den Venen. Sie weisen vielmehr auf einen Rückstrom des Bluts nach beendeter Austreibung hin. Bei dieser

1) Meine Beobachtungen erstrecken sich nur auf solche Fälle, in denen die Frequenzänderung spontan oder im Anschluss an eine Aenderung der Gefässfüllung auftrat; unter andern Umständen (wie bei Vagusreizung u. a.) liegt die Sache natürlich anders. 
Auffassung finden beide Erscheinungen, der jähe Abfall sowie seine prompte Beendigung ibre einfache und ungezwungene Erklärung. Man muss sich diesen Ruickstrom im Anschluss an die analogen Untersuchungen am Säugethierherzen ${ }^{1}$ ) wohl folgendermaassen entstanden denken.

Durch die energische Contraction des Herzmuskels wird der ausgetriebenen Blutmasse eine gewisse eigene Geschwindigkeit ertheilt, welche geniigt, um im Augenblick des Aufhörens der treibenden Kraft am Ausgangspunkte gegenïber dem hochgespannten Aortendruck eine Stelle niedrigeren Druckes entstehen zu lassen. Die Ausgleichung dieser Druckdifferenz erfolgt durch ein Rückfluthen der Welle, welches wiederum durch den Schluss der Semilunarklappen eine plötzliche Hemmung erfährt. Wir haben also in Punkt 4 Fig. $2=$ d Fig. 5 den Moment des Klappenschlusses zu erblicken. Der Klappensehluss bewirkt durch die Hemmung des Rückstroms, dass die Ausgleichung jener Druckdifferenz nur unvollständig stattfindet, so dass der intracardiale Druck nach dem Schluss der Semilunarklappen niedriger ist als der Aortendruck und trotz andauernder Contraction des Ventrikels viel geringer bleibt als der Aortadruck. Denn der schon stark zusammengezogene Ventrikel bringt keine grosse Kraft mehs auf; auch ist die in der Herzhölle befindliche Blutmenge verscbwindend klein. Folglich ist eine nochmalige Eröffnung der Semilunarklappen ausgeschlossen.

Die Riuckstaung oder um mit Grashey zu reden, die „negative Welle" pflanzt sich, wie dieser Forscher ebenfalls nachgewiesen, nach der Peripherie fort. Wir finden also den Klappenschluss auch im Puls der Cruralarterie ausgeprägt, natirlich mit entsprechend geringerer Druckschwankung einhergehend. Den kurzen steilen Abfall, welcher, wie wir g'esehen, den Klappenschluss zur Folge hat, bezeichne ich im Folgenden nach dem Vorgang von Grashey als "negative Klappenschlusswelle" oder auch als Klappenschlussrückstrom. Eine "positive Klappenschlusswelle" wie sie am erwähnten Ort $\$ 111$ für den Menschen aufgestellt wird, kommt im Kaltblütergefässsystem wohl wegen der Kleinheit der den Rückstrom erzeugenden Druckdifferenzen nieht mehr zur Ausbildung. Die Tiefe der negativen Welle hängt ab von der Schnellig-

1) Grashey, die Wellenbewegung in elast. Röhren u. s. w. Leipzig 1881. $\S 32$ u. ff. 
keit der centrifugalen Bewegung des Blutes ${ }^{1}$ ) und diese wiederum von der Druckdifferenz zwischen Arterienwurzeln und Venenenden Ein relatives Maass für die Grösse dieser Druckdifferenz gibt uns die Grösse der pulsatorischen Schwankung. Wir finden es demnach begreiflich, dass wir mit dem Abnehmen der letzteren (wie sie z. B. nach Blutverlusten eintritt) auch die Klappenwelle immer unbedeutender werden und schliesslich ganz verschwinden sehen. Mit der Tiefe dieser Welle ändert sich natürlich auch die Steilheit des Abfalls in gleichem Sinne. -

An all den Curven, welche bei gleichzeitiger Markirung der beobachteten Herzbewegung aufgenommen sind, zeigt sich, dass die mehrfach erwähnte Abknickung im letzten Theil des Abstiegs (bei 5 in Fig. 3), sofern dieselbe uberhaupt vorhanden ist, unmittelbar nach dem Beginn der Diastole erfolgt. Andererseits ergab bei allen Curven, bei denen jene Abknickung iberhaupt in die Erscheinung tritt, die Berechnung ihrer Lage, dass sie zeitlich zwischen die Punkte $d$ und e des Cowl-Gad'schen Cardiogramms oder mit Punkt e zusammenfällt; immer kommt sie erst nach dem Beginn der Diastole (nach d); ich nenne sie desshalb kurz „diastoliche Abknickung". Die constante Wiederkehr dieses Verhältnisses legte die Vermuthung nahe, dass es sich hier nicht um ein zufälliges zeitliches Zusammentreffen bandle, sondern dass vielmehr jene plötzliche Veränderung in der Raschheit des Abfalls mit dem Eintritt der Diastole in ursächlichem Zusammenhang stehe. In welcher Weise wir uns die Wirkung der Diastole zu denken haben, kann ich nicht bestimmt angeben, doch scheint mir die folgende Erklärung nicht unwahrscheinlich.

Durch die Diastole wird den Venenenden eine bedeutende Menge Blut entzogen; dadurch wird die Spannungsdifferenz zwischen Arterien und Venen vergrössert. Mit der Grösse dieser Differenz wächst natürlich auch die Schnelligkeit der Strömung vom Orte höheren nach dem Orte niedrigen Druckes und mit dieser Beschleunigung des Abflusses ist das raschere Sinken des Drucks in den Arterien gegeben.

Besonders deutlich tritt diese Beschleunigung des Abfalls hervor, wenn durch Blutentziehung die systolische Füllung des arteriellen Systems bedeutend herabgesetzt oder wenn überhaupt,

1) Grashey l, c. $\$ 36$. 
gleichgiltig aus welcher Ursache, die pulsatorische Druckerhöhung gering ist. Die Gründe hiefür sind (die Richtigkeit der für die ganze Erscheinung gegebenen Erklärung vorausgesetzt) einfacher Natur. Der Blutstrom wird nach Beendigung des Aorteneinstroms ausschliesslich durch die in den Arterienwänden aufgespeicherten Spannkräfte in die Venen hinübergetrieben. Es ist nun klar, dass mit der Menge des systolisch in die Aorta geworfenen Blutes auch jene Spannkräfte zunehmen; sind diese aber sehr gross, so wird von Anfang an der Strom nach den Venen und damit (nach Beendigung des Aorteneinstroms) die Druckverminderung mit bedeutender Geschwindigkeit vor sich gehen. Zu der Zeit, wo die Diastole einsetzt, ist der Druck schon bedeutend gesunken, und damit die treibende Kraft erheblich kleiner geworden. Es müsste demnach eine Verlangsamung des Abfalls eintreten. Diese wird aber durch den Beginn der Diastole und die mit demselben ein. tretenden günstigeren Bedingungen für den Abfluss aufgewogen und wir bekommen einen gleichmässig steilen Abstieg, wie ihn die meisten völlig normalen Curven zeigen (conf. Fig. 2). Bei abnorm gesteigerter Herzfüllung (z. B. durch Transfusion physiologischer Kochsalzlösung), welche eine bedeutende Pulsgrösse bedingt, finden wir in der That die erste Wirkung der Arterienspannung so gross, dass die mit Beginn der Diastole eintretende Beschleunigung des Abfalls latent bleibt und derselbe gegen das Ende zu langsamer erscheint (siehe Fig 11). Das umgekehrte ist der Fall, wenn durch schlechte Füllung und in Folge davon geringe Dehnung der Arterien wenig Spannkräfte aufgespeichert werden. Der erste Abstieg ist dann langsam - ja es kann sogar noch nach Beendigung des Aorteneinstroms der Druck auf der erreichten Höhe verharren und erst wenn durch den mit dem Einsetzen der Diastole beginnenden Blutabfluss aus den Venenenden eine bedeutendere Druckdifferenz erzeugt wird, tritt ein rascherer, oder überhaupt erst ein Abfall ein.

Es bleibt uns jetzt noch übrig, die vor Beginn des Anstiegs zuweilen auftretende kleine Erhebung (Fig. 4 bei v und Fig. 8 II) zu deuten. Eine sichere Erklärung für dieselbe zu geben, bin ich jetzt nicht im Stande. Durch die zeitliche Analyse ist festgestellt, dass sie stets ganz in den Bereich der Martius'schen "Verschlusszeit" fällt (ohne sich jedoch immer mit derselben vollständig zu decken). Man könnte demnach an eine durch die factisch vorhandene Form- und Lageveränderung des Ventrikels bedingte 
Dehnung oder Compression des Bulbus arteriosus denken, welche gentigen würde, um eine vorübergehende Drucksteigerung von $1-2 \mathrm{~mm} \mathrm{Hg}$ zu erzeugen. Geichzeitige eardiographische und manometrische Aufzeichnung dürfte wesentlich zur Aufklärung dieser Verhältnisse beitragen.

Es sei mir gestattet, an dieser Stelle noch mit einigen Worten auf die Bedeutung der langen Systolendauer einzugehen. Dass die Ventrikelcontraction mindestens bis zum Schluss der Semilunarklappen währt, ist von Ceradini experimentell bewiesen, von Martius (l. c.) am Menschen festgestellt worden; letzterer hält sogar eine etwas längere Dauer derselben flir möglich, also ein Verhältniss, ähnlich demjenigen, wie wir es eben für das Krötenherz festgestellt haben. Zweifellos haben wir darin eine wesentliche Sicherung des Klappenmechanismus zu erblicken; denn abgesehen von der physiologischen Insufficienz, welche nach Martius durch einen Rückfluss des Blutes in den erschlafften Ventrikel bedingt wäre, hätten die halbmondförmigen Klappen, wenn sofort nach Beendigung des Aorteneinstroms die Erschlaffung einträte, der intraventriculäre Druck also plötzlich mindestens auf Null sänke, einen gewaltigen und jähen Anprall des rückstauenden Blutstroms auszuhalten, der namentlich bei hohem arteriellem Drucke leicht eine Schädigung derselben im Gefolge haben könnte. Wenn aber die Systole noch einige Zeit über den Klappenschluss hinaus andauert, so brauchen wir darin, glaube ich, keine überflissige Arbeitsleistung des Herzens zu sehen (wie dies Martius zu thun scheint); es erscheint im Gegentheil als eine sebr zweckmässige Einrichtung, dass zu einer Zeit, in welcher der arterielle Druck zwar nicht mehr seine maximale, aber doch noch eine recht bedeutende Höhe hat, dieser nicht voll auf den Klappen lastet, indem sie von der Herzseite her (bei bestehender Systole des Herzens) gewissermaassen gestiitzt und gegengedrickt werden. Auch bei den Warmblütern dürfte, namentlich in Anbetracht der von Fick und Hürthle ${ }^{1}$ ) nachgewiesenen bedeutenden Grösse der pulsato-

1) 1. c. p. 426 . 
rischen Schwankung, ein analoges Verhalten nicht unwahrscheinlich sein.

Eine Beeinflussung der Pulscurve durch die Athmung, etwa analog der respiratorischen Schwankung bei Warmblütern liess sich nicht feststellen. Eine in grösseren Perioden sich vollziehende Schwankung ist schon dadurch ausgeschlossen, dass die Athmung meist ungefähr dieselbe Frequenz zeigt, wie die Herzaction. Wir missten also innerbalb der einzelnen Pulswelle eine characteristische Marke finden; doch ist eine solche nicht vorhanden; auch wird die Curve durch Sistirung der Athmung in keiner Weise verändert ${ }^{1}$ ). Nur wenn ausnahmsweise stark schnappende Athembewegungen vorkamen, welche den ganzen Rumpf mit erschlitterten, ubertrugen sich diese Störungen, wie ich nicht selten sah, auch anf die Pulscurve; ebenso musste bei den Versuchen am Arcus aortae während des Zeichnens die Athmung unterbrochen werden, weil durch dieselbe die an den Musculus sterno-hyoideus sich anlehnende Cantile erschüttert wurde.

Die normale Pulscurve der Schlangenaorta zeigt die meiste Aehnlichkeit mit dem Cruralispuls der Kröte. Auf genaue zeitliche Auswerthung derselben wurde verzichtet.

\section{Theil.}

\section{Künstliche Beeinflussung des Blutdrucks und seiner Schwankungen.}

Im ersten Theil dieser Arbeit musste ich wiederholt, dem vorgesteckten Plane der Untersuchung vorgreifend, Thatsachen erwähnen, welche schon in das Gebiet der künstlich herbeigeführten Aenderungen der normalen Verhältnisse gehörten. Es war dies unumgänglich nothwendig, da uns eben die durch willkürliche Umgestaltung der Versuchsbedingungen erzielten Resultate (unter der Voraussetzung, dass sie constant sind) ein wesentliches Hiilfsmittel bei Erklärung der normalen Vorgänge bieten, ja man kann sagen, als solches unentbehrlich sind. Der Leser möge sich daher nicht wundern, wenn er in den folgenden Capiteln manches im vorhergehenden Abschnitt schon Berührte wiederfindet.

1) Gompertz (I. c. S. 249) weist nach, dass durch die Funktion des Lungenleberbandes eine Beeinflussung der Herzthätigkeit durch die Athmung verhindert wird. 
Die ersten in Frage kommenden Eingriffe sind die bei der Präparation nothwendig werdenden mehr oder minder bedeutenden Verletzungen. Es liesse sich denken, dass schon die bei Blosslegung der Arteria cruralis häufig vorkommende und bei kleinen Thieren eigentlich unumgängliche Eröffnung des Lymphsacks genatgte, um Störungen der Circulation hervorzubringen. Diesbeztigliche Versuche ergaben jedoch ein vollständig negatives Resultat. Auch die Resection des Kreuzbeins oder des halben Sternums hatten keine nachweisbare Wirkung; oder jedensfalls ist dieselbe so kur\% dauernd, dass sie sich zu einer Zeit, wo das Versuchsthier mit dem registrirenden Apparat in Verbindung gesetzt war, nicht mehr bemerklich machte. Die Präparation bleibt demnach ohne Einfluss auf unsere Curven (ausser für den Fall, dass wir etwa die oben bezüglich der spontanen Drucksenkung ausgesprochene Vermuthung als der Wirklichkeit entsprechend annehmen wollten). Die Eröffnung des Herzbeutels, welche ich einige Mal vornahm, zeigte keinerlei Wirkung auf die Druckcurve. Einen Punkt will ich hier berühren, den ich fruher tibergangen habe, um die Bemerkungen über die Methode der Untersuchung nicht allzu ausführlich werden zu lassen, ich meine die Narcose. Meist wandte ich reinen Aether oder eine Mischung von Aether und Chloroform zu gleichen Theilen an. Da ich schon bei den ersten Versuchen die Erfahrung machte, dass bei einigermaassen tiefer Narcose sehr bald Athemstillstand eintritt, beschränkte ich mich, um die unangenehmen Folgen desselben zu vermeiden, später auf das geringste zur Präparation absolut nothwendige Maass der Anästhesirung, und benützte dann der rascher vorübergehenden Wirkung halber stets reinen Aether, so dass zu einer Zeit, wo die Registrirung der Pulscurve begann, die Wirkung des Narcoticums verflogen war. Meine Curven sind also eigentlich von nicht nareotisierten Thieren gewonnen; dies gilt ganz besonders von denjenigen, welche die Untersuchung der normalen Verbältnisse bezweckten. Einmal ergab sich nach Anwendung von Chloroform während des Versuchs eine geringe Herabsetzung des Blutdrucks; ebenso einmal nach subcutaner Injection von Curare. Specielle auf diesen Punkt gerichtete Untersuchungen babe ich nicht angestellt. 
1) Veränderungen der Pulscurve erzeugt durch Variation der Gefässfüllung.

Die Herabsetzung des Blutgehaltes wurde erreicht durch Aderlass und zwar wurde bei Kröten meist die Arteria cutanea magna, in einzelnen Fällen auch die gleichnamige Vene oder die Vena abdominalis benutzt; bei Schlangen erfolgte die Blutentziehung durch Anschneiden der Arteria carotis. Zum Zwecke übernormaler Füllung injicirte ich physiologische Kochsalzlösung $(0,6 \%)$ und zwar bei Kröten meist in die Vena cruralis, zuweilen auch in die Vena abdominalis; bei Schlangen in die Vena jugularis.

Beztiglieh der Menge des entzogenen Bluts bezw. der infundirten $\mathrm{NaCl-lösung} \mathrm{begnügte} \mathrm{ich} \mathrm{mich} \mathrm{stets} \mathrm{mit} \mathrm{ungefähren} \mathrm{Schätzungen.}$

\section{A. Blutentziehung.}

Die erste Wirkung eines unbedeutenden Aderlasses ist stets eine Senkung des Blutdrucks, verbunden mit Verkleinerung der Pulsgrösse und der negativen Klappenschlusswelle. Die Form der Curve erleidet zunächst keine gröbere Veränderung. Sehr bald tritt aber die frijher beschriebene diastolische Abknickung scharf hervor. Wird Blut aus einer Vene entnommen, so treten die Symptome der Anämie natürlich viel langsamer auf, als beim Anschneiden einer Arterie; in ihrem Wesen bleiben sie sich gleich. Bei sehr reichlicher und rascher Blutentziehung durch Anschneiden einer grossen Schlagader, wie der Arteria cutanea magna oder der Carotis, fällt der Druck momentan sehr stark. So lange das Blut ausfliesst, zeigt das Manometer keine oder nur sehr unbedeutende Pulsschwankungen an (natürlich erst nachdem eine gewisse Menge ausgeflossen ist); sofort aber oder wenigstens bald nach der Unterbindung des Gefässes treten wieder, wenn auch nur schwach entwilckelte Pulse auf, welche nach einiger Zeit an Grösse zunehmen. Sie zeigen uns aber ein von den normalen Pulsen völlig abweichendes Bild, und wenn uns nicht die zeitliche Analyse bestimmte Anhaltspunkte darböte, und nicht ganz allmähliche Uebergänge zur normalen Form vorlägen, dürfte eine einheitliche Erklärung der so verschiedenen Gestalten ziemlich schwer fallen.

Fig. 8 veranschaulicht die Wirkung eines plötzlichen starken Aderlasses. Curve I ist vor demselben gezeichnet, II einige Zeit 
nach Anschneidung der Art. cutanea magna, III nach stärkerem Blutverlust, IV wurde etwa 15 Minuten nach Unterbindung der Arterie gewonnen, wo schon eine theilweise Erholung stattgefunden hatte. Die Cantile lag in der Aorta communis.

Fig. 8.

Druckeurven der Aorta communis von Bufo. I Normal. II Nach Blutentziehung aus der Arteria cutanea magna. III Nach stärkerer Blutentziehung. IV Etwa 15 Min. nach Beendigung des Aderlasses.

Fig. 9 zeigt verschiedene Stadien der Erholung. In Curve I sehen wir Pulse, wie sie zuerst nach einem reichlichen Blutverlust wieder auftreten; II-IV sind von einem andern Thier gewonnen, kurze Zeit nach einer unbedeutenden Blutentziehung aus der Arteria pulmonalis sinistra. Hier befand sich die Canüle im Arcus aortae. Die ersten Pulse, welche wieder eine deutlich ausgeprägte Form besitzen, zeigen nach einem kurzen, nicht sehr steilen Anstieg (wenigstens nach bedeutender Blutung) eine lange Verharrung auf der Höhe, welche mit einer deutlichen Knickung der Curve (s. Fig. 9 II) in den Abstieg ïbergeht. Nach einiger Zeit sehen wir in der 
Mitte der langen Verharrung eine leichte Einknickung (Fig. 9 II und III bei k) auftreten, indem zugleich der vor derselben liegende Theil an Höhe etwas zunimmt. Diese Einknickung entpuppt sich mit fortschreitender Besserung als identisch mit der negativen Klappenschlusswelle, während die ersterwähnte Abknickung den erfolgten Beginn der Diastole anzeigt. Die Gründe für das Verschwinden der Klappenschlusswelle sowie für das schärfere Hervortreten der diastolischen Abknickung nach Verminderung der Gefässfulllung habe ich oben bei Erklärung der Pulsform erörtert. Mit der allmählichen Rickkehr der Pulse zur normalen Form und Grösse geht gleichzeitig eine Wiedererhöhung des Blutdrucks einher.

Fig. 9.

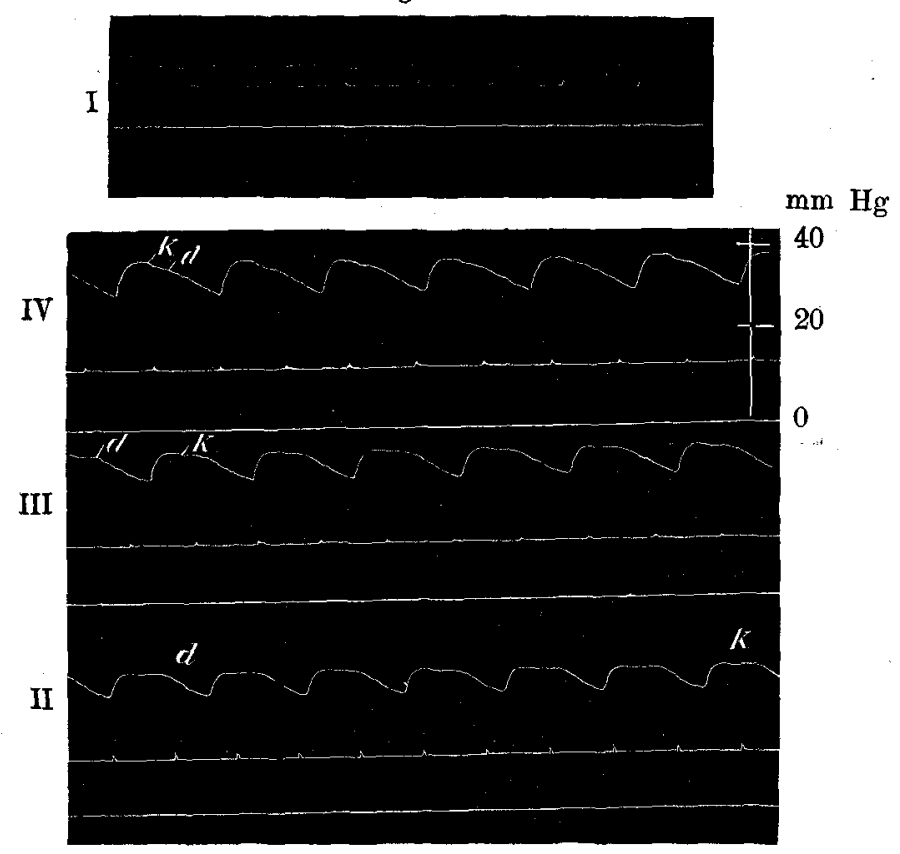

Blutdruckcurven vom linken Aortenbogen von Bufo. I Unmittelbar nach Beendigung eines starken Aderlasses. II, III, IV (von einem andern Exemplar.) Allmähliche Erholung nach einem schwächeren Aderlass; (bei drei unmittelbar auf einander folgenden Trommelumgängen gewonnen).

In keinem Fall sah ich während des Versuchs eine vollständige Wiederherstellung der normalen Verhältnisse eintreten; immer blieb der Mitteldruck etwas unter dem ursprünglich vorhandenen; während ich den Puls in verhältnissmässig kurzer Zeit, 
etwa 20-30 Minuten, die alte Form und Grösse wieder erreichen sah (wenn der. Blutverlust nicht gar zu gross gewesen). Ich will damit nicht sagen, dass der Druck sich nicht mehr zur früheren Höhe erheben könne; ich halte dies im Gegentheil für sebr wohl möglich und bei genügend langer Beobachtung sogar für wahrscheinlich. Nach sebr starken (ja mitunter nach verhältnissmässig kleinen) Blutentziebungen findet aber eine solche vollständige Erholung gewöbnlich nicht statt; es macht sich vielmehr nach nicht allzulanger Zeit eine Schädigung des Herzens bemerklich, die sich in Störungen des Rhythmus kund giebt; doch hiertiber später.

Die relative Dauer der einzelnen Phasen anlangend zeigte die gleichzeitig mit der Aufnahme der Pulscurve ausgeführte Markirung der beobachteten Herzbewegung, dass Systole und Diastole in ihrem zeitlichen Verhältniss unverändert bleiben. In Uebereinstimmung damit ergab die Berechnung der diastolischen Abknickung selbst bei starker Anaemie dieselbe Lage wie bei Curven, die unter ganz oder nahezu normalen Bedingungen gezeichnet waren. Anders liegt die Sache für die übrigen in der Pulscurve hervortretenden Abschnitte. Sie erleiden mit fortschreitendem Blutverlust zum Theil eine wesentliche Aenderung ihrer Dauer. Die Messungen konnten natürlich nur an solehen Pulsen vorgenommen werden, an denen das Ende des Aorteneinstroms sowie der Klappenschluss noch scharf markirt sind. Ausserdem eignen sich die bei den höchsten Graden von Blutarmuth oder in den ersten Stadien der Erholung gezeichneten Curven auch desshalb nicht zu Messungen, weil durch den hierzu nöthigen raschen Trommelgang die ohnebin wenig imponirenden Höhenunterschiede vollends verwischt werden.

Trotzdem nun auf Grund dieser technisehen Schwierigkeiten nicht die Extreme verglichen werden können, sind die zu Tage tretenden Veränderungen doch bedeutend und charakteristisch genug, um das waltende Gesetz erkennen zu lassen. Sie erklären sich ausnahmslos rein physicalisch aus dem verschlechterten Füllungszustand des Gefässsystems und der dadurch bedingten mangelbaften diastolischen Herzfüllung. Der Aorteneinstrom wird verkürzt und zwar geschieht dies wesentlich auf Kosten des Anstiegs; natiillich, denn je weniger Flüssigkeit in die Aorta eintritt, um so früher wird der Punkt erreicht sein, wo Einstrom und Abfluss sich gleich werden. Die Verharrung bleibt ziemlich gleich oder kann sogar etwas verlän- 
gert werden. Zugleich verliert der Anstieg an Steilheit; denn abgesehen von der geringen Menge des ausgeworfenen Blutes arbeitet das diastolisch sehr wenig gedehnte Herz sicherlich auch viel weniger kräftig, als das ausreichend stark diastolisch gedehnte. Im Anschluss an die frübere Beendigung des Aorteneinstroms erfolgt auch der Riickstrom und damit der Klappenschluss etwas früher. Folglich wird der Zeitraum zwischen Sehluss der Semilunarklappen und Beginn der Diastole, da die Systole des Herzens nicht verkuirzt wird, länger; hier unter diesen abnormen Verhältnissen können wir sagen, leistet der Ventrikel überflussige Arbeit. Zur Illustration der geschilderten Veränderungen theile ieh das Resultat zweier systematischen Blutentziehungsversuche mit ${ }^{1}$ ). Ausser der absoluten Dauer der einzelnen Phasen gebe ich zugleich das Verbältniss derselben zur Länge der ganzen Pulswelle an: (S. 390, 391).

In beiden umstehend mitgetheilten Versuchen war die Blut- entziehung von einer (allerdings unbedeutenden) Frequenzverminderung, sowie wiederum die Vermehrung der Gefässfüllung von einer Beschleunigung der Pulsfolge begleitet. Diesem Umstande haben wir es zu danken, dass die Vergleichung der bei verschiedenem Blutgehalt für die einzelnen Curvenabschnittte gefundenen Zeitwerthe iberhaupt sichere Schliusse erlaubt. Das angenehmste wäre natürlich, wenn sich die Frequenz überhaupt nicht änderte; einen derartigen Fall konnte ich leider unter meinen Versuchen nicht finden. Ich sah aber anch rerschiedentlich im Gefolge eines Aderlasses eine bedeutende Vermehrung der Herzschläge; unter diesen Umständen geht der Verkürzung des Aorteneinstroms eine solche der ganzen Palswelle parallel und wir sind dann nicht im Stande zu unterscheiden, ob die eine durch die andere bedingt ist oder ob beide unabhängig von einander bestehen. Umgekehrt können wir unter Bedingungen wie die der obigen Versuche, wo sich die beiden in Frage kommenden Grössen (Austreibungszeit und ganze Welle) in entgegengesetztem Sinne ändern, mit um so grösserer Sicherheit ihre gegenseitige Unabhängigkeit behaupten. Wir kommen also zu dem Schluss, dass mit Vergrösserung oder Verkleinerung der Gefässfüllung die Dauer des Aorteneinstroms sich gleichfalls vergrössert, beziehungsweise

1) Beziiglich der Messungen verweise ich auf die technischen Vorbemerkungen. 


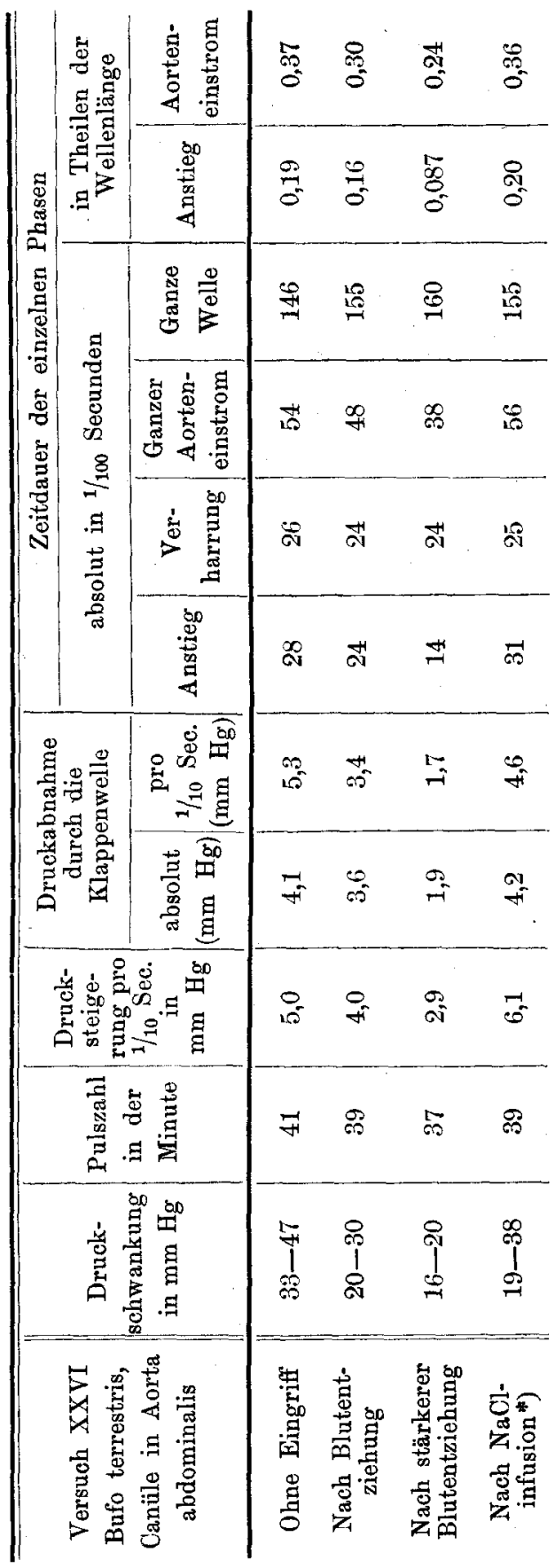


Beiträge znr Lehre vom Kreislauf der Kaltblüter.

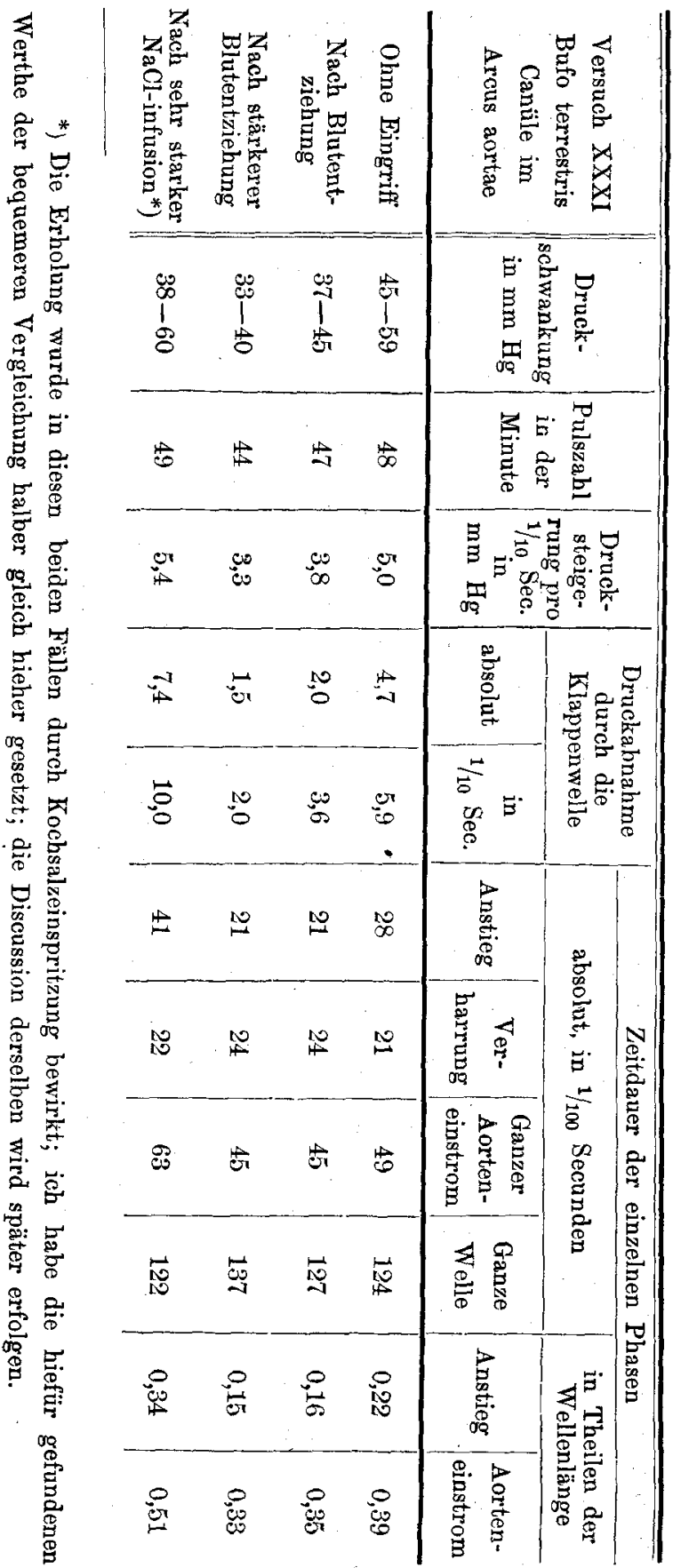


verkleinert, ohne Rïcksicht darauf, ob oder was für eine Aenderung in der Frequenz der Herzkontraction eintritt.

Zweifellos werden mit wechselndem Blutgehalt auch bedeutende Schwankungen des zeitlichen Verhältnisses der "Verschluss"eit" zur Austreibungszeit vorkommen; ein Urtheil daruber kann ich nir nicht erlauben, da natürlich nur die gleichzeitige Aufnahme von Cardiogramm und Pulscurve hier zu unanfechtbaren Resultaten führen kann und ich solche Versuche leider nicht mehr anstellen konnte.

Halten wir die in diesem Capitel besprochenen Ergebnisse zusammen mit den Angaben von Marey und $\mathrm{Hürthle}{ }^{1}$ ) über die Beziehung der Pulsgrösse zum Blutdruck, so stossen wir auf einen bedeutsamen Gegensatz zwischen Warm- und Kaltblittern. Hürthle hat an Kaninchen und Katzen den Nachweis geliefert, dass mit Herabsetzung des Blutdrucks, auch wenn sie durch Blutentziehung herbeigefihht, also mit einer Verschlechterung der Gefässfüllung verbunden ist, der pulsatorische Druckzuwachs stets bedeutend an Grösse sowohl als an Schnelligkeit zunimmt; ja die letztere kann nach seinen Angaben sogar bis viermal so gross werden als bei hohem Druck. Erst in vorgeschrittenem Stadium der Verblutung sinkt die Grössse der pulsatorischen Schwankung unter den Normalwerth, während dies beim Kaltbluter augenblicklich eintritt.

Zwei Momente sind es zweifellos, welche diesen Gegensatz veranlassen: einmal geht beim Warmblïter die einzelne Herzcontraction mit bedeutend grösserer Schnelligkeit vor sich als beim Kaltbliter, was wir sowohl direct beobachten können, als auch aus der Form der Druckeurve schliessen müssen; zweitens ist die relative Menge des mit jeder Systole in die Aorta geworfenen Blutes bei Kaltbliutern aller Wahrscheinlichkeit nach viel grösser als beim Warmbliiter; es wird demnach bei den ersteren die Herzflillung schon im Anfang der Blutentziehung viel mehr beeinflusst werden als bei den letzteren ${ }^{2}$ ).

1) 1. c. p. 434 .

2) Den ersten der beiden Gründe, den Einfluss der verschieden raschen Herzcontraction vermochte ich experimentell nachzuweisen. Der Apparat, dessen ich mich dazu bediente, war folgendermaassen zusammengestellt: Eine Spritze mit graduirtem Stempel vertrat den Ventrikel. Dieselbe stand durch ein T-rohr, an dessen beiden freien Schenkeln sich 2 Ventile befanden, die in 
B. Transfusion physiologischer Kochsalzlösung.

Nachdem ich die Umgestaltung der Druckeurve durch Blutentziehung eingehend geschildert habe, kann ich mich bei Besprechung der Transfusionswirkung um so kürzer fassen. In

ihrer Stellung den Atrioventricular- und Semilunarklappen entsprechen, in Verbindung mit langen elastischen Schläuchen, deren eine Hälfte (welche eng und dickwandig war) die Arterien, deren andere (weit und dünnwandig) die Venen vertrat. Die periphere Verbindung wurde hergestellt durch eine kurze Glasröhre. In der Nähe der Verbindungsstelle wurde ein Widerstand eingeschaltet durch eine Klemmschraube, welche den Schlauch beliebig zu comprimiren gestattete. Im arteriellen Schlauchsystem wurden durch Einschaltung von T-röhren 2 Seitenöffnungen angebracht; die erste diente der Ver. bindung mit dem registrirenden Manometer, an der zweiten befand sich eine halbgefüllte Spritze mit Hahn, welche den Zweck hatte, eine bequeme Aenderung des arteriellen Drucks zu ermöglichen. Die Druckschwankungen wurden auf einer berussten $\mathrm{R}$ othe'schen Trommel verzeichnet. An diesem Kreislaufsschema erhielt ich nun durch rasche Pumpenstösse (gleichgiltig in welchen Zwischenräumen sie sich folgten) Curven, welche grosse Aehnlichkeit mit Blutdruckcurven der Warmblüter zeigen. Fig. 10 I nnd II stellen so gewonnene Curven dar, III zeigt die normale Carotiscurve einer Katze (gezeichnet von $\mathrm{H}$ ürthle), IV die Carotiscurve eines Kaninchens (nach gelinder Reizung des Nv. depressor. Zur Erzeugung einer dem Kaltblüterpuls ähnlichen Anstiegsform musste der einzelne Stoss im Ganzen langsam verlaufen und gegen das Ende noch langsamer werden.

Fig. 10.

I und II Künstliche Curven I bei höherem II bei niedrigem Druck. III Normale Carotiscurve der Katze. IV Carotiscurve vom Kaninchen nach gelinder Reizung der nv. depressor. 
welcher Weise der Blutdruck des normalen Thiers durch Transfusion beeinflusst wird, kann ich nicht angeben, da ich dieselbe immer erst nach vorgängiger Blutentziehung vornahm.

Bei diesen Versuchen ergab sich die Thatsache (welche eben für die Erklärung des geschilderten Gegensatzes wichtig ist), dass: wenn der Pumpenstoss rasch erfolgt, bei niedrigem arteriellen Druck eine geringere ausgeworfene Flüssigkeitsmenge eine grössere Drucksteigerung hervorruft, als bei hohem Aortendruck selbst eine grössere Flüssigkeitsmenge zu erzeugen vermag. Natürlich gilt dies nur innerhalb gewisser Grenzen, die ich jedoch nicht anzugeben vermag. Erfolgt dagegen die Austreibung langsam, so nimmt mit der ausgetriebenen Menge auch der durch dieselbe erzeugte Druckzuwachs ab, auch wenn der arterielle Druck gleichzeitig gesunken ist. Die theoretische Ableitung dieser Sätze aus hydrodynamischen Gesetzen vermag ich auf Grund der wenigen gelegentlichen Versuche, die ich anstellte, nicht zu geben. Vermuthlich spielt die verschiedene. Geschwindigkeit der centrifugalen Flüssigkeitsbewegung hierbei eine wesentliche Rolle. -

Nicht so einfach lässt sich die relativ grössere Ventrikelcapacität der Kaltblüter darthun; wir sind hier mehr auf Wahrscheinlichkeitsrechnungen angewiesen. Landois (Lehrbuch der Physiologie $§ 97$ ) giebt an, dass Säugethierblutkörperchen, in die seitliche Bauchvene eines Frosches eingespritzt, bis zum Wiedererscheinen in der andern Vene 7-11 also im Mittel 9 Secunden gebrauchen. Wir müssen jedoch bedenken, dass diese Werthe nicht ohne weiteres vergleichbar sind mit den für Warmblüter gefundenen Kreislaufszeiten, da wir bei den Amphibien keinen geschlossenen kleinen Kreislauf haben. Die eingespritzten Blutkörperchen haben vielmehr vom Herzen aus drei Wege (Aorta, Carotis, Pulmonalis), und von den in der Bauchvene zuerst wieder ankommenden (welche $\mathrm{L}$ andois jedenfalls beobachtet hat) ist gewiss anzunehmen, dass sie den nächsten Weg, d. h. den durch die Aorta gemacht haben. Landois hat also nur die Zeit gemessen, in der die Blutmenge des Aortenkreislaufs einmal das Herz passirt. Nehmen wir die im Mittel gefundene Frequenz von 48 Schlägen in der Minute zur Berechung (wobei also die Dauer der einzelnen Pulswelle 1,25 Secunden beträgt), so entfallen auf jene Zeit $\frac{9}{1,25}=7,2$ Systolen. Es würden hiernach mit jeder Systole ein Siebentel bis ein Achtel der Blutmenge, welche der Aortenkreislauf zu fassen vermag, in denselben geworfen, während beim Warmblüter etwa nur ein Dreizehntel bis ein Vierzehntel der Blutmenge des grossen Kreislaufs $(=1 / 27$ der ganzen Blutmenge) mit jeder Herzaction in das Arteriensystem geworfen wird.

Anders können wir uns, glaube ich, die Thatsache, dass bei Kaltblütern der pulsatorische Druckzuwachs trotz der langsamen Herzcontraction relativ ebenso gross ist, wie beim Warmblüter $(=1 / 3$ des Minimaldrucks) kaum erklären, als eben durch die Annahme, dass durch die Systole jedesmal eine verhältnissmässig viel grössere Blutmenge in die Arterien befördert wird. 
Im grossen Ganzen sehen wir im Anschluss an die Kochsalzeinspritzung die durch den Aderlass herbeigefubrten Veränderungen einfach wieder verschwinden, ähnlich wie bei der allmählichen Erholung, nur bedentend rascher: Der Druck hebt sich wieder, der Anstieg wird rascher, die Pulsschwankung nimmt an Grösse zu. Ebenso gewinnt die negative Klappenschlusswelle an Tiefe und Steilheit und die diastolische Abknickung verschwindet allmählich wieder oder verliert wenigstens an Deutlichkeit. Der Anstieg und damit auch der ganze Aorteneinstrom werden wieder länger. Aber neben dieser im Allgemeinen vorhandenen Aehnlichkeit zeigen sich zwischen den normalen und den nach Ersatz eines Theils des Blutes durch physiologische Kochsalzlösung gewonnenen Curven doch bestimmt hervortretende Unterschiede, welche in den specifischen Eigenschaften der injicierten Lösung sowie in den durch die Injection geschaffenen mechanischen und dynamischen Bedingungen ihre Erklärung finden.

In keinem Fall gelang es mir, auch wenn die intravenöse Injection unter starkem Druck geschah, den vor der Blutentziehung vorhandenen arteriellen Mitteldruck wiederherzustellen. Dagegen ist der pulsatorische Druckzuwachs sowie die Tiefe und Steilheit der Klappenwelle in solchen Fällen nach der Transfusion meist beträchtlicher als vorher bei normaler Blutfullung. Diese Thatsache zeigt sich auch in den im letzten Abschnitt mitgetheilten Versuchen XXVI und XXXI. Auch finden wir, wenn nach erfolgter Transfusion ein neuer Aderlass vorgenommen wird, eine viel raschere Erbolung der Pulsgrösse (aber nicht des Druckes) als nach einer am normalen Thier vorgenommenen Blutentziehung. Die folgenden Versuche mögen dies darthun. (S. folg. Seite).

Wir sehen hier, wie in den oben mitgetheilten Versuchen nach theilweisem Ersatz des Blutes durch Salzwasser denselben oder sogar geringeren Mitteldrücken bedeutend grössere Pulsschwankungen entsprechen.

Dieselbe Erscheinung tritt auch auf - natürlich in geringerem Grade, - wenn wir nach einer bedeutenden Blutentziehung die allmähliche Erholung abwarten. Mehrere Versuche, von denen ich einen hier mittheile, lassen dieselbe erkennen:

Fig. 11 S. 397 zeigt die Druckeurve des linken Aortenbogens, I nach ganz geringer, II nach sehr reichlicher Transfusion.

Bezüglich der Frequenz ist zu bemerken, dass in Fällen, wie 
Versuch XXVII Bufo. Canüle in der Aorta communis.

\begin{tabular}{c||c|c|c}
\hline Eingriff & $\begin{array}{c}\text { Druck- } \\
\text { schwankung } \\
\text { in mm Hg }\end{array}$ & Differenz & $\begin{array}{c}\text { Mittel- } \\
\text { druck }\end{array}$ \\
\hline $\begin{array}{c}\text { Kleiner Blutverlust } \\
\begin{array}{c}\text { Minuten nach } \\
\text { starkem Aderlass }\end{array}\end{array}$ & $36-43$ & 7 & 38 \\
$\begin{array}{c}\text { 10 Minuten } \\
\text { nach demselben }\end{array}$ & $20-22$ & 2 & 21 \\
$\begin{array}{c}\text { Nach NaCl- } \\
\text { transfusion }\end{array}$ & $32-42$ & 10 & 35 \\
$\begin{array}{c}\text { Transfusion } \\
\text { wiederholt }\end{array}$ & $29-46$ & 17 & 35 \\
$\begin{array}{c}\text { Minuten nach } \\
\text { starkem Aderlass }\end{array}$ & $12-15$ & 3 & 13 \\
$\begin{array}{c}\text { Minuten nach } \\
\text { demselben }\end{array}$ & $16-21$ & 5 & 18 \\
\end{tabular}

Versuch XXXII Bufo. Canüle im Arcus aortae.

\begin{tabular}{c||c|c|c}
\hline Eingriff & $\begin{array}{c}\text { Druck- } \\
\text { schwankung } \\
\text { in mm Hg }\end{array}$ & Differenz & $\begin{array}{c}\text { Mittel- } \\
\text { druck }\end{array}$ \\
\hline Normal & $\begin{array}{c}45-59 \\
38-50\end{array}$ & 14 & 50 \\
$37-45$ & 8 & 42 \\
$26-32$ & 6 & 28 \\
Etwa 30 Minuten \\
später
\end{tabular} \mid $\begin{array}{ccc}33-48 & 15 & 38\end{array}$

die mitgetheilten, wo dieselbe mit der Blutentziehung gesunken war, die Transfusion wieder eine Steigerung der Pulszahl hervorbrachte, doch nur bis zu einem gewissen Grade. Machte ich nach einer sehr reichlichen Injection den Versuch, durch erhöhten Druck noch grössere Fluissigkeitsmengen einzuführen, so trat mehrmals Verlangsamung der Schlagfolge oder auch Störung des Rhythmus auf, wie sie Fig. 12 auf folgender Seite zeigt. 
Die nach reichlichem Blutverlust wieder eintretende Steigerung des Blutdrucks, sowie die Thatsache, dass es nicht gelingt, durch Injection von Kochsalzlösung den Blutdruck beliebig zu er-

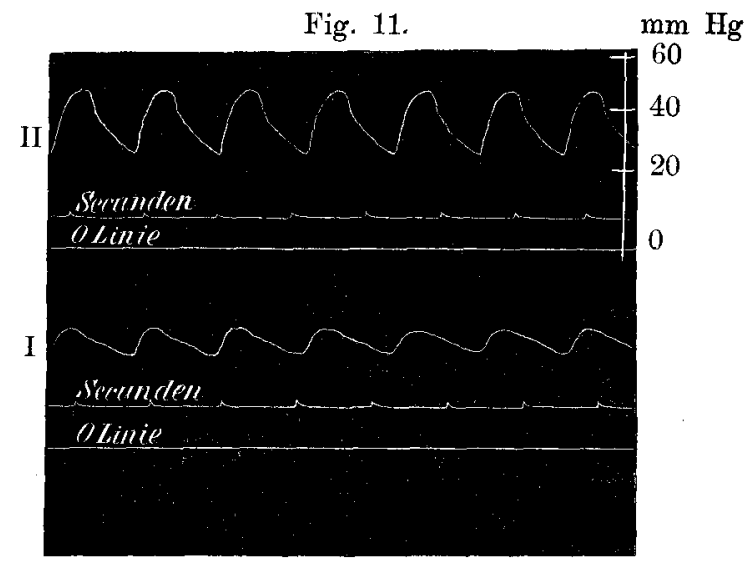

Druckcurve des Aortenbogens von Bufo. I nach unbedeutender, II nach reichlicher Salzwassertransfusion.

höhen, müssen uns darauf führen, auch im Kaltblïter-Organismus Einrichtungen anzunehmen, deren Zweck ist, den Blutdruck innerhalb gewisser Grenzen constant zu erhalten. Regéczy ${ }^{1}$ ) hat ge-

Fig. 12 $\mathrm{mm} \mathrm{Hg}$

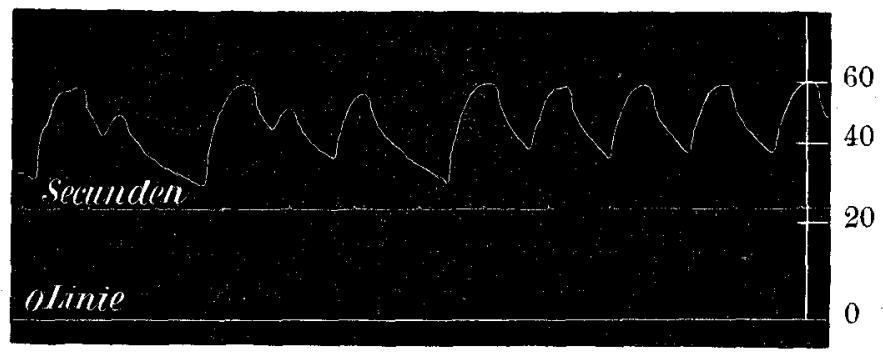

Druckcurve des Aortenbogens von Bufo. Störungen des Rhythmus unmittelbar nach forcierter Transfusion.

genüber der von Worm-Müller und Lesser gemachten Annahme einer besondern Accommodationsfähigkeit des Gefässsystems die physikalischen Vorgänge der Diffusion und Filtration als Ursache der Stabilität des Blutdrucks bei Warmblittern behauptet.

1) Dies Archiv Bd. XXXVII p. $73-106$.

E. Pflüger, Archiv f. Physiologie. Bd, XLIV. 
Sehen wir zu, wie sich die Ergebnisse unserer Kaltblüterversuche mit jenen Anschauungen vereinigen lassen. Wenn wir einer Kröte oder Schlange nach einem Aderlass physiologische Kochsalzlösung in eine Vene einfliessen lassen, so tritt zu einer Zeit, wo die eingeflossene Menge noch nicht sehr beträchtlich ist und wo namentlich der normale Mitteldruck noch lange nicht erreicht ist, eine bedeutende Transsudation auf, die bei weiterer Fortsetzung der Infusion so mächtig wird, dass das Thier geradezu trieft. Wo die Präparationswunde einen Einblick erlaubt, sehen wir die Zwischenräume zwischen den Muskeln und andere Gewebslücken in förmliche Seen verwandelt. Wir können also hier den von $R$ egéczy erschlossenen Vorgang direct sehen und damit erscheint die Unmöglichkeit beliebiger Drucksteigerung sofort selbstverständlich. Ebenso können wir die andere Seite der Regéczy'schen Erklärung, die Annabme der Diffusion oder allgemeiner ausgedrückt, die Flüssigkeitsaufnahme in die Gefässe als wesentliche Ursache der Wiedererhöhung des Blutdrucks auch für den Kaltblitter behaupten. Schon die lange Zeit, welche zur Erbolung nothwendig ist (eine vollständige Wiederherstellung des normalen $\mathrm{Zu}$ stands habe ich nie beobachtet) spricht gegen die hypothetische Accommodationsfähigkeit als alleinige Ursache derselben; denn dass, und zwar für den Warmbltiter in viel höherem Grade als für den Kaltbliuter, das Gefässsystem sich dank seinen contractilen Elementen seinem Inhalt anpasst, ist ja ausser Zweifel ${ }^{1}$ ).

Damit gewinnen wir ein weiteres Moment für die Erklärung des klein bleibenden Mitteldrucks nach Kochsalzeinspritzung. Denn die dadurch bewirkte Verdlinnung des Gefässinhalts wird den Diffusionsstrom aus den Lymphräumen nach den Gefässen abschwächen, wenn nicht ganz zum Stillstand bringen.

In der eben beriihrten Verdinnung des Blutes erblicke ich auch die Ursache der Pulsvergrösserung in Folge der Transfusion.

Nach C. A. Ewald ${ }^{2}$ ) und Andern erhöbt der Wassergehalt des Blutes bedeutend dessen Strömungsgeschwindigkeit (speciell im Capillargebiet). Es wird also eine viel raschere Ausgleichung der Druckdifferenz zwischen Arterien und Venen erfolgen; das

1) Siehe hierüber die wichtige Arbeit von Cohnstein und $Z u n t z$, dies Archiv Bd. 42, S. 317.

2) Du Bois-Reymond's Arch. 1887, p. 208. 
arterielle Druckminimum wird in Folge dessen tiefer gerïckt. Das arterielle Druckmaximum aber muss erhöht werden; denn ein schnelleres Strömen des Blutes erzeugt seinerseits bei gleicher Frequenz des Herzschlags eine stärkere diastolische Herzftillung und dadurch mittelbar eine Vergrösserung des pulsatorischen Druckzuwachses und (wie oben auseinandergesetzt) eine Verlängerung des Aorteneinstroms.

Aus der beschleunigten Strömung ${ }^{1}$ ) erklärt sich auch die bedeutende Tiefe und Steilheit der negativen Klappenschlusswelle nach dem frïher Gesagten ohne weiteres.

Auf Grund der vorstehenden Betrachtnngen liesse sich auch die merkwirdige Thatsache, dass nach allmählicher Erholung von der Anämie dem gleichen Mitteldruck eine grössere Pulsschwankung entspricht, einfach erklären: Die Drucksteigerung geschieht ja wesentlich durch Aufnahme der diunnflitssigen Lymphe in das Blut; der Wassergehalt des Blutes wird also vermehrt und damit kommen wir durch dieselbe Schlussfolgerung zu einer - natülich geringeren - Pulsvergrösserung wie bei directer Verdunnung des Blutes durch Salzwasser. Es mögen ausserdem noch andere Umstände mitwirken, welche sich unserer Kenntniss entziehen.

Anhangsweise erwähne ich noch hier ein paar Thatsachen, die ich bei diesen Versuchen beobachtet habe.

In Versuch XXXI (s. Tabelle auf S. 391) war die Herzfüllung im unmittelbaren Anschluss an die Injection (zu der die Vena abdominalis benützt war) zu der Zeit, wo das Manometer die in Fig. 12 wiedergegebenen Störungen der Curve anzeigte und noch einige Zeit nachher, so bedeutend, dass während der Systole, wie ich durch directe Beobachtung des Herzens controliren konnte, der Ventrikel sich nicht völlig entleerte. $O b$ in diesem Fall der schon ziemlich contrahirte Herzmuskel nicht mehr im Stande war einen höheren Druck aufzubringen, oder ob die Austreibung aus irgend einem andern Grund vor völliger Entleerung ihr Ende erreichte, vielleicht auch vor dem Schluss der Semilunarklappen verhältnissmässig viel des dünnflüssigen Blutes ins Herz zurückfloss, vermag ich nicht anzugeben.

Welch bedeutenden Einfluss die diastolische Herzfüllung auf die Grösse

1) Es wäre nicht uninteressant zu untersuchen, wie sich der Puls ändert, wenn man nicht die überaus fluide Kochsalzlösung, sondern eine andere weniger flüssige (etwa die kürzlich empfohlene Zuckerlösung) dem Blute beimischte. Leider fehlte mir die Zeit, derartige Versuche anzustellen. 
der Pulsschwankung ausübt, zeigt folgender Befund: In einem Versuch, bei dem der linke Aortenbogen zur Einführung der Canüle benutzt wurde, zeigten sich im Anfang des Versuchs sehr flache Pulse, wie sie nach Blutverlust aufzutreten pflegen. Die genaue Untersuchung ergab, dass der nach Entfernung der linken Sternalhälfte stehen gebliebene Musculus sternohyoideus auf das Herz drückte und so die diastolische Erweiterung beeinträchtigte. Nach Durchtrennung des Muskels traten augenblicklich kräftige Pulse auf. Vorher betrug die Schwankung 41-51, der Mitteldruck 44, nachher die Schwankung 38-56, der Mitteldruck $44 \mathrm{~mm} \mathrm{Hg}$.

Schliesslich sei hier ein Phänomen kurz besprochen, das mir bei Beobachtung des blossgelegten Herzens wiederholt auffiel und das ich um so weniger übergehen möchte, als es von anderer Seite unter andern Umständen beobachtet, eine wesentlich verschiedene Deutung erfahren hat. Wenn man nämlich dem Thier Blut entzieht, so tritt nach kurzer Zeit, wenn noch relativ wenig ausgeflossen ist, ein Stadium ein, in dem das diastolische Herz nicht mehr gleichmässig roth, sondern weiss und roth getupft aussieht. Nach einiger Zeit, wenn der Blutdruck sich wiedererholt hat, tritt auch die gleichmässige Färbung wieder auf. In den "Verhandlungen der Berliner physiologischen Gesellschaft"1) theilt Pohl-Pincus dies Phänomen mit (er nennt das Aussehen des Herzens treffend: "schachbrettartig marmorirt"), führt dasselbe jedoch auf starke elektrische Reizung der Haut zurück. Er sagt am erwähnten Ort: „Einem kräftigen Frosch wird das Vorderhirn abgetrennt oder zerstört; bei grösserer Blutung: Tampon. Der Thorax über dem Herzen wird gefenstert. Es wird abgewartet, bis . . . . . . .

Nun wird (etwa 4 Secunden lang) ein starker electrischer Strom mittels Nadeln auf die Haut eines Schenkels geleitet, so dass der Frosch stark zuckt . . . . . (dann tritt das Phänomen auf).

Auf Grund meiner Beobachtungen wurde ich sofort auf die Stelle aufmerksam: „bei grösserer Blutung Tampon“. Ich wiederholte daher den Pohl-Pincus'schen Versuch an mehreren kräftigen Fröschen mit peinlicher Vermeidung jeglichen Blutverlustes. Die Hautgefässe der Stirn wurden unterbunden, das Schädeldach sorgfältig abgehoben; sodann führte ich mit einem feinen Unterbindungshaken einen Seidenfaden unter dem Vorderhirn durch, schnürte dasselbe ab und zerquetschte es dann. Der leer gewordene Theil der Schädelhöhle wurde sofort sorgfältig mit Feuerschwamm austamponirt und die ganze Wunde mit solchem bedeckt. Auch die Eröffnung des Thorax geschah mit sorgfältiger Vermeidung jeder Blutung. Jetzt konnte ich die Schenkelhaut minutenlang mit den stärksten Strömen (Inductorium mit Eisendrahtkern, 1 Daniell, Rollenabstand 0 ) reizen, so dass der Frosch sehr stark zuckte und - die Marmorirung blieb aus. Darauf entfernte ich die Tampons, reizte wieder und nach kurzer Zeit zeigte sich die erwartete Veränderung.

1) Du Bois-Reymond's Arch. 1886, p. 549. 
In einem andern Versuch führte ich dieselbe durch Anschneiden der Vena abdominalis herbei und dabei konnte man zugleich sehen, dass durch die heftigen Zuckungen der Blutverlust wesentlich gefördert wurde.

In einem Fall verwendete ich ein schwächliches Thier, bei der Operation fand ein kleiner Blutverlust statt; nach Eröffnung des Thorax zeigte sich die marmorirte Diastole schon ausgeprägt.

In einem letzten Versuch endlich, in dem das Thier straff angebunden und dadurch der Brustgürtel etwas flach gedrückt war, trat das Phänomén ohne vorgängigen Blutverlust auf. An den beftigen Contractionen betheiligte sich nämlich auch die Bauchmuskulatur (vielleicht durch Stromschleifen gereizt). Dadurch wurden die gesammten Baucheingeweide nach oben gepresst und die Herzbasis gegen den Rand des stehen gebliebenen Sternalrestes gedrückt und so die vollständige Füllung des Ventrikels verhindert. Sobald ich die Befestigung des Thiers etwas lockerte und den Rest des Steruums mit der Pincette aufhob, : um dem Herzen Raum zum Ausweichen zu geben, kehrte die normale diastolische Färbung wieder.

Ich fasse demnach die Erscheinung einfach als Folge schlechter Herz. füllung auf, welche in der Mehrzahl der Fälle im Blutverlust begründet sein wird. Die Möglichkeit einer Erholung hat bei Berücksichtigung der vorstehend mitgetheilten Thatsachen nichts Auffälliges an sich; es braucht ja. nur eine Ruhepause einzutreten, in der die verletzten Gefässe sich verstopfen können; dann ersetzt sich das Ausgeflossene wenigstens zum Theil wieder. Dagegeu müsste, wie ich glaube, wenn es sich um eine Reizwirkung handelte, unter sonst gleichen Bedingungen die Erholung regelmässig wiederkehren, wenn wir nicht eine individuell sehr verschiedene Empfindlichkeit annehmen wollen; viel einfacher erklären sich die (in dieser Beziehung) schwankenden Versuchsergebnisse aus der Annahme verschieden grosser Blutverluste (wobei ausserdem noch der Blutreichthum des Thiers vor dem Versuch in Betracht kommen mag).

Ebenso kann das Verschwinden der Abnormität, wenn durch Vagusreizung diastolischer Herzstillstand hervorgerufen wird, nicht gegen meine Auffassung sprechen.

Die zweite von Pobl-Pincus als Abnormität bezeichnete und auf dieselbe Ursache zurückgeführte Erscheinung, die Zweitheilung der Diastole anlangend, bin ich in der Lage mitzutheilen, dass ich dieselbe häufig an Kröten- und Froschherzen, die abgesehen von der Thoraxöffnung unter vollständig normalen Bedingungen arbeiteten, beobachtet habe. Das Zusammenfallen der Vorhofscontraction mit dem zweiten Theil der Diastole können wir nach den Ergebnissen der mehrerwähnten cardiographischen Untersuchungen von Cowl und Gad, welche gleichzeitig Curven von Vorhof und Ventrikel aufnahmen, wohl nicht mehr, wie Pohl-Pincus angiebt, als "Störung des geeigneten Ineinandergreifens zwischen Vorhof und Ventrikel" ansehen, da uns in jenen Curven dies Verhältniss als das normale entgegentritt. 


\section{Arhythmische Herzthätigkeit.}

Häufig sah ich an Kröten sowohl als an Ringelnattern im Verlaufe des Versuchs ein plötzliches Aufhören der rhythmischen Herzaction. An deren Stelle trat dann eine ausgesprochene Periodik in der Art, dass Gruppen rhythmischer Pulse mit diastolischen Stillständen abwechselten. Das Bild solch intermittirender Pulscurven wird durch die verschiedene Grösse der Gruppen, sowie die verschiedene Dauer der Pausen ein sehr wechselvolles. Am häufigsten fand ich die Form, bei der sich wenige Pulse zu je einer Gruppe vereinigen und die einzelnen Gruppen durch kurze Stillstände getrennt sind. Die Zahl der Pulse innerhalb einer Gruppe ist im einzelnen Fall sehr gleichmässig. Besteht jede Gruppe nur aus einem einzigen Puls, so entsteht ein sehr verlangsamter Rhythmus, bei dem die einzelnen Herzrevolutionen sich in grossen Zwischenräumen folgen.

Eine eventuelle Erholung kann entweder allmählich erfolgen, in der Art, dass von Gruppe zu Gruppe die Zahl der Einzelpulse zunimmt, während gleichzeitig die Pausen sich verkürzen, oder aber plötzlich, indem einfach im Anschluss an einen Herzstillstand der normale Rhythmus wieder einsetzt.

Während des diastolischen Herzstillstandes findet eine allmähliche Ausgleichung der Spannungs-Differenz zwischen Arterien und Venen, und damit eine bedentende Senkung des arteriellen Drucks statt. Zugleich wird das Herz iber normal gefullt und stark gedehnt. Dieser Umstand in Verbindung mit dem geringen Widerstand, den der gesunkene Aortendruck darbietet, haben eine enorm vergrössernde Wirkung auf die Höhe sowobl, als die Steilheit der Drucksteigerung, welche durch die erste nacb der Pause eintretende Kammercontraction hervorgebracht wird.

Diese Wirkung nimmt mit der Dauer der Pause begreiflicher Weise an Intensität zu. Schon nach ziemlich kurzdauerndem Stillstand gentigt die erste Systole trotz der starken Herzfullung nicht, um soviel Blut in die Aorta hinüber zu befördern, dass der normale Spannungsunterschied zwischen Arterien und Venen hergestellt wïrde. Es fliesst also wenig Blut nach den Venen, der arterielle Druck sinkt entsprechend wenig. Die gute diastolische Herzfullung dauert dagegen an. Die nun folgende zweite Systole wird daher den nur wenig gesunkenen Aortendruck wieder um 
ein Beträchtliches erhöhen; so bekommen wir das Bild einer aufsteigenden Treppe. Meist ist schon mit dem zweiten (seltener erst mit dem dritten oder schon mit dem ersten) Puls die normale Druckhöhe wieder erreicht und die folgenden zejgen nichts Abnormes mehr, bis mit dem Eintreten der Pause das Spiel wieder von neuem beginnt. In einem Fall lagen jedoch auch die Gipfel der ersten Pulse höher als die der zweiten und der folgenden.

Auch die von Langendorff ${ }^{1}$ ) beobachtete „periodische Frequenzänderung ${ }^{\star}$ kam mir im Verlauf der arhythmischen Herzaction za Gesicht, doch bin ich nicht im Stande, ihr eine bestimmte Stellung in der Entwicklung derselben anzuweisen. Der Uebergang vom langsamen zum raschen (normalen) Rhythmus und umgekehrt erfolgte meist durch Bildung kleiner Gruppen. - In den Fällen, wo die Gruppenbildung bis zum Ende des Versuchs bezw. bis zum Tod des Thieres bestehen blieb, zeigte sich eine fortschreitende Abnahme des Blutdrucks, verursacht durch zunehmende Schwäche der Systolen.

Den Verlauf einer solchen Störung der normalen Herzthätigkeit in Zahlen wiederzugeben, halte ich um so mehr für überfliussig, als es mir nicht gelungen ist, irgend eine bestimmte Beziehung zwischen Pulszahl und Dauer der Gruppen und Länge der Pausen festzustellen. Aus den numerischen Verhältnissen irgend einen Schluss auf den Grad der Affection zu ziehen, ist vorläufig nicht möglich; doch wird man unbedenklich annehmen können, dass langdanernde Stillstände nur von kleinen Gruppen oder einzelnen Pulsen unterbrochen, schwereren Störungen des normalen Zustandes entsprechen, und mit geringerer Wahrscheinlichkeit eine Erholung erwarten lassen, als zahlreiche Gruppen und kurze Pausen.

Die längsten Stillstände, welche ich (ausnahmsweise) beobachtete, dauerten ca. 4 Minuten; meist beschränkte sich ihre Dauer anf wenige Secunden.

Wir baben bisher die bestehende arhythmische Thätigkeit des Herzens betrachtet, ohne uns um die Bedingungen ihres $\mathrm{Zu}$ standekommens zu kümmern. In all den Fällen, in denen periodische Herzaction im Verlauf des Versuchs auftrat, liess sich eine vorausgegangene Schädigung des Thiers nachweisen und zwar stets eine solche, welche entweder längere Zeit eingewirkt

1) Du Bois-Reymond's Arch. 1884, Supplement. 
hatte oder die in ihren Folgen nicht mehr oder wenigstens nicht mehr vollständig zu beseitigen war. In der Mehrzahl der Fälle war starker Blutverlust oder absichtliche Blutentziehung vorangegangen; bemerkenswerth ist, dass die Periodik sich oft erst ziemlich lange nach Stillung der Blutung entwickelte. In andern Versuchen fehlte die Respiration; auch hier trat das Phänomen erst nach lang dauerndem Athemstillstand auf. Sofort trat derselbe ein in einem Fall, wo dem Thier (Bufo) eine geringe Menge 25 procentiger Magnesialösung durch die Aorta rückwärts ins Gefässsystem gelangt war. Bei einer Ringelnatter, welche vor dem Versuche 2 Stunden in einem Blechgefäss der Mittagssonne ausgesetzt war (die Temperatur in dem Gefäss betrug $41^{\circ} \mathrm{C}$.), trat ebenfalls kurz nach Beginn des Versuchs periodische Herzthätigkeit (mit sehr langen Stillständen) ein. Hier wie in den meisten Versuchen zeigte sich die bemerkenswerthe Thatsache, dass die Störung des Rhythmus im unmittelbaren Anschluss an eine electrische Vagusreizung begann, so einmal bei einer Ringelnatter ${ }^{1}$ ), auf welche keine der angeführten Schädlichkeiten, wie Blutverlust, Athemstillstand etc. eingewirkt hatten. Wenn in andern Fällen die häufig wiederholte Vagusreizung keinen Erfolg in der angedeuteten Richtung batte, so spricht dies nicht gegen die obige Annahme; denn auch die andern als Ursachen der Rhythmusstörung angegebenen und wie z. B. die Erstickung auch von andern Forschern, wie Langendorff (1. c.), Rossbach ${ }^{2}$ ) u. a. angenommenen Schädlichkeiten haben durchaus nicht immer den erwarteten Erfolg. So zeigte eine Kröte, der beide Lungen (durch seitliche Schnitte in die Bauchdecken hervorgezogen) und Arteriae cutaneae magnae sowie die gleichnamigen Venen (zur Beschränkung der Hautathmung) unterbunden waren, nach elf Stunden, trotzdem das Blut ganz dunkel war, noch vollkommen normalen rhythmischen Puls, während sonst die Periodik nach spätestens einer halben bis einer Stunde begann. Beachtenswerth bleibt dabei, dass bei diesem Thier weder electrische noch chemische Reizung des einen oder andern Vagus eine Hemmungswirkung auslöste. Ein völlig spontanes Eintreten der Arhythmie habe ich nie beobachtet.

Sind wir schon bezüglich der Ursachen, welche die arhyth-

1) Das Thier war gravid wie die meisten der benützten Schlangen.

2) Nach Hofmaun und Schwalbe, Jahresberichte etc. Bd. III p. 44. 
mische Herzthätigkeit hervorrufen, auf Schlüsse nach dem Grundsatz: post hoc ergo propter hoc angewiesen, so betreten wir erst recht einen unsichern Boden, wenn wir versuchen die Mittel anzugeben, durch welche eine dauernde oder wenigstens zeitweilige Wiederherstellung des Rhythmus erzielt werden kann. Oftmals wird nämlich eine wohl ausgebildete Periodik plötzlich obne nachweisbare Ursache von einer langen Reihe rbythmischer, normal frequenter Pulse unterbrochen (diejenige Rhythmik, bei welcher die einzelnen Pulse durch lange Pausen getrennt sind, balte ich nicht für wesentlich verschieden von der eigentlichen Gruppenbildung). Meine diesbeztiglichen Versuche, eine normale Rhythmik wieder herzustellen, sind nicht zahlreich genug, um allgemeine Schliusse aus ihnen ziehen zu können; doch mögen folgende Versuche dazu dienen, einiges Thatsächliche in dieser Frage beizubringen.

Versuch Nr. II. Bufo terrestris. Narcose: 0,05 gr Chloralhydrat subcutan (der einzige Fall, in dem ich dies Narcoticum gebrauchte). Es fehlt die A thmung (wohl in Folge zu tiefer Narcose). Nach einiger Zeit beginnt whe vorhergehende Frequenzänderung plötzlich eine wohlausgebildete Periodik (Gruppen von 3 Pulsen, Pausen von 2 Secunden). Die Haut des Thiers war sehr trocken; von der Vermuthung ausgehend, dass dies einen nachtheiligen Einfluss auf die Hautathmung des Thiers ausüben könne, benetzte ich dasselbe und der Rhythmus des Herzens kehrte (wenigstens für die Daver des Versucbs) zurück. Versuch Nr. XXII. Bufo terrestris. Mässige Narcose mit Aether. Es fehlt die Athmung. Es tritt bald "periodische Frequenzänderung" ein. Es wird künstliche Athmung eingeleitet in der Weise, dass eine mit einem elastischen Ballon verbundene Kanüle durch den Mund in die Glottis gesteckt wird und die Lungen in dem der normalen Athmung etwa entsprechenden Tempo aufgebläht werden. Bei dem ersten Aussetzen der Athmung - während des Pumpens wird die Pulscurve so gestört, dass sie kein Urtheil über die Herzaction erlaubt - zeigten sich einzelne Pulse durch Pausen von 4 Secunden getrennt, also keine Besserung. Die künstliche Athmung wird fortgesetzt. Nach ca. 11/2 Minuten ist normale Pulsation vorhanden. Nach weiteren $1 \frac{1}{2}$ Minuten, während welcher die Respiration auf dis beschriebene Weise unterhalten wurde, war ebenfalls normaler Rhythmus zu constatiren, welcher etwa nach 20 Secunden einer bedeutenden Verlangsamung der Herzschläge und nach noch einmal so langer Zeit einer deutlichen Gruppenbildung (Gruppen zu 3 Pulsen, Pausen zu 2 Secunden) Platz macht. Später kamen grössere Gruppen, sowie verlangsamte Einzelpulse; im weiteren Verlauf trat für 2 Minuten normale Herzthätigkeit ein. Nach dem Wiedererscheinen der Periodik wurde die Kehlhaut mit starken Strömen ge- 
reizt, worauf einige Athembewegungen erfolgten; die Curve bleibt von da an 2 Minuten lang normal. Nach Wiederkehr der Gruppen wird kurze Zeit künstlich respirirt. Im Anschluss daran bleibt der wiedereingetretene normale Rhythmus, trotzdem das Thier nicht athmet, für den Rest des Versuchs (etwa $1 / 2$ Stunde) ungestört.

Wie oben mitgetheilt, erfolgt häufig auf Blutentziehung arhythmische Herzthätigkeit, die auch durch Kochsalztransfusion nicht verschwindet, ja trotz derselben mitunter noch zu Stande kommt, oder kommen kann. Einmal verschwand die in Folge eines Aderlasses bestehende Periodik durch Uebergiessen des Thieres mit physiologischer Kochsalzlösung. Zugleich stieg hierbei der Blutdruck um $10 \mathrm{~mm} \mathrm{Hg}$, vielleicht in Folge langsamer Resorption besagter Flissigkeit. -

Es bleibt mir noch tibrig, einen Eingriff zu besprechen, in dessen Gefolge mit solcher Regelmässigkeit eine zeitweilige Wiederherstellung der normalen Pulsrhythmik erschien, dass von einem rein zufälligen Zusammentreffen schlechterdings keine Rede sein kann, ich meine die Reizung des peripheren Vagusstumpfes mit starken Strömen.

Immer gelang es durch diese Manipulation, Pulsreihen von normaler Frequenz hervorzurufen, die tiber eine Minute sich erstrecken konnten. Die Wirkung zeigte sich stets am Schlusse der Reizung oder einige Secunden später. Rein bekommen wir dieselbe, wenn wir die Hemmungsfasern des Vagus durch Atropin lähmen; unterlassen wir diese Maassregel, so zeigt sich die Wiederherstellung der Rhythmik als Nachwirkung, wenn die Hemmungswirkung voriber gegangen ist. Diese Wirkungsweise des Vagus ist, wie ich erst bei Zusammenstellung meiner Resultate bemerkte, schon von Heidenhain ${ }^{1}$ ) am ausgeschuittenen Froschherzen constatirt worden. An Ringelnattern konnte ich eine solche Vaguswirkung nicht mit Sicherheit nachweisen. Fig. 13 I und II und Fig. 14 I und II geben Beispiele ausgesprochener Periodik sowie des abnorm verlangsamten Rhythmus. Fig. 15 sfellt die Wirkung einer Vagusreizung (nach Atropinisirung: 1 Daniell $50 \mathrm{~mm}$ Rollenabstand) dar. Der hierdurch erzeugte normale Herzschlag dauerte $1 \frac{1}{2}$ Minute.

Es erhebt sich die Frage, wo wir uns den Sitz der die Pe-

1) Dies Arch. Bd. XXVII p. 397. 
Beiträge zur Lehre vom Kreislauf der Kaltblüter. 


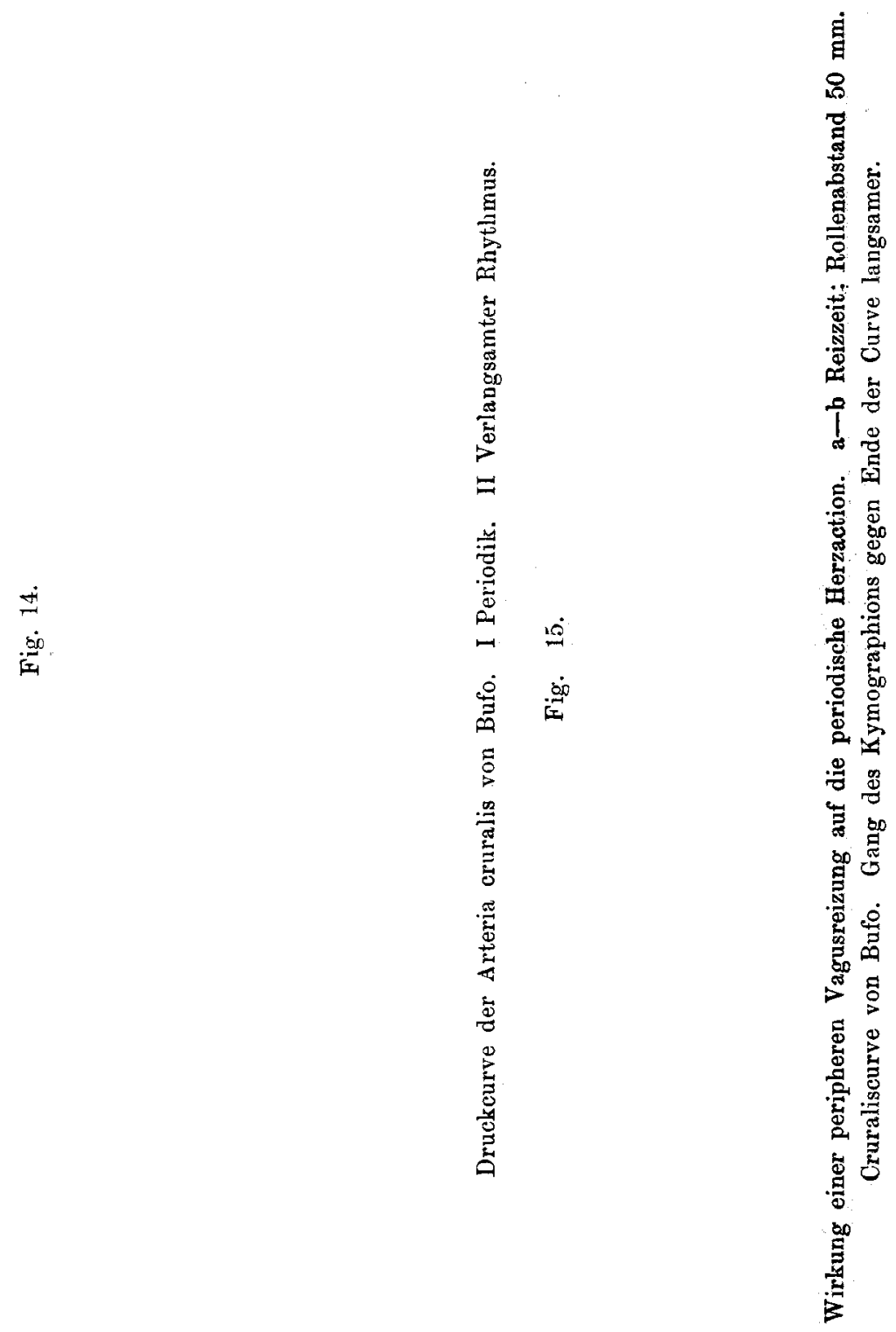


riodik bedingenden Ursachen zu denken haben. Als ich das Phänomen zum erstenmal sah, dachte ich zunächst an eine centrale Vagusreizung als nächste Ursache; allein es zeigte sich bei späteren Versuchen, dass die Durchschneidung beider Vagi auf die Entstehung sowohl, als auf die Weiterentwicklung der schon bestehenden Gruppenbildung ohne jeden Einfluss blieb. Ebenso zeigten andere Versuche, dass Atropingaben, welche die Hemmungswirkung der Vagi prompt aufhoben, weder das Auftreten der Arbythmie hinderten, noch auch den normalen Rhythmus zurückzuftihren oder nur die Periodik zu ändern vermochten. Auch die Durchschneidung des Riickenmarks erwies sich als vollständig indifferent. Wir haben somit den Angriffspunkt für die Schädigung, welche die Umwandlung der rhythmischen Herzthätigkeit in die periodische veranlasst, ins Herz selbst zu verlegen.

Dies beweisen auch die Versuche Luci-

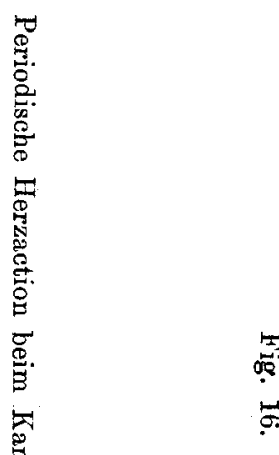
ani's ') am isolirten Froschherzen, ebenso wie die Beobachtungen Langendorff's ${ }^{2}$ ) an abgeklemmten Theilen desselben. Auch Heidenhain ${ }^{3}$ ), welcher die arhythmische Herzthätigkeit beim Hund ${ }^{4}$ ) hervorrief, wies durch Lösung aller

1) Berichte d. sächs. Academie, Math.-phys. C1. 1873.

2) 1 . c.

3) Dies Archiv Bd. V S. 143.

4) Ich führe hier an, dass ich gelegentlich anderer Versuche eine sehr schön ausgeprägte Periodik der Herzaction an einem Kaninchen beobachtete, nachdem längere Zeit auf beiden Vagis, von denen der eine durchscbnitten war (auf diesem letzteren abwechselnd peripher und central), Wattebäuschchen, welche mit Amylalkohol $(0,5: 100 \mathrm{Aq}$.$) getränkt waren) gelegen hatten. Bemer-$ kenswerth ist, dass das Thier, an dem ich diese Beobachtung machte, in der Nacht zuvor geworfen hatte; bei andern Kaninchen erhielt ich nach ebenso langer Einwirkung desselben Giftes keine Arhythmie. Fig. 16 giebt ein Stück der interessanten Curve wieder. 
Verbindungen des Herzens mit dem nervösen Centralapparat die Ursachen der Periodik als im Herzen selbst gelegen nach. Ueber die Vorgänge, welche sich im Anschluss an die Einwirkung einer Schädlichkeit innerhalb der Herzganglien oder der Muskelsubstanz oder endlich zwischen beiden abspielen und die Umwandlung der rhythmischen in die periodisch aussetzende Thätigkeit herbeiführen, enthalte ich mich jeder Hypothese.

3) Sensible Reizung. Erwärmung.

Ich fasse in diesem Kapitel die Ergebnisse einiger gelegentlich der Untersuchung der normalen Blutdruckverbältnisse angestellter Versuche kurz zusammen.

Durchschneidung und Reizung des Nervus ischiadicus erzeugte stets eine Erhöhung des Blutdrucks. Dieselbe betrug im Mittel etwa $10 \mathrm{~mm} \mathrm{Hg}$. Ebenso gelang es mir durch electrische Reizung der Haut eine Blutdrucksteigerung $z \mathfrak{u}$ erhalten. Der Blutdruck blieb meist noch einige Zeit nach der Reizung auf der erreichten Höhe; bei sehr kurzen Reizungen kam es vor, dass sogar nach Schluss derselben noch eine Steigerung erfolgte; bei sehr lang dauernden Reizen trat sofort nach Schluss derselben oder schon vorher eine Senkung ein. Soweit meine an Kröten angestellten Versuche reichen, bestätigen sie also vollkommen die von Hellweger ${ }^{1}$ ) und Joseph ${ }^{2}$ ) für den Frosch gemachten Angaben. Neu durfte die Beobachtung sein, dass auch einfaches Anblasen des Thiers genügt, um eine wenn auch unbedeutende Blutdrucksteigerung zu bewirken. Auch bei Schlangen erhielt ich durch electrische Reizung der Haut eine Erhöhung des Blutdrucks. In den meisten Fällen ging der Drucksteigerung eine Frequenzvermehrung (um 2-8 Schläge in der Minute) parallel.

Plötzliche starke Erwärmung einer aus dem Kreislauf ausgeschalteten Extremität erhöhte den Blutdruck einmal um 10, ein anderes Mal um $14 \mathrm{~mm} \mathrm{Hg}$ (unter gleichzeitiger Beschleunigung der Pulsfolge um 4 Schläge); ein drittes Mal blieb sie ohne Wirkung. Gelinde Erwärmung des ganzen Thieres (wobei also die unmittelbare Wirkung der Wärme auf das Herz nicht ausge-

1) Berliner klinische Wochenschrift 1879 p. 649.

2) Du Bois-Reymond's Arch. 1879 Supplement p. 56. 
schlossen war), erhöhte während ca. 1 Minute den Druck um $7 \mathrm{~mm} \mathrm{Hg}$, die Frequenz um 5 Schläge. Abkuiblung durch Auflegung feuchter Watte hob die Wirkung auf. Langdauernde Erwärmung einer Kröte durch Auflegen von in warmem Wasser (ca. $50^{\circ}$ C.) getränkter Watte, die immer wieder ernenert wurde, brachte die Frequenz von 40 auf 60 Schläge in der Minute; dabei hob sich der Druck nur um $4 \mathrm{~mm}$ Hg. Abkühlung führte die urspringlichen Verbältnisse zurïck.

Besser als Kröten eignen sich Schlangen zu Versuchen über Wärmewirkung. Dieselben lassen sich bequem erwärmen, indem man sie in einen Cylinder mit doppelten Wänden steckt, zwischen denen Wasser von bestimmter Temperatur fliesst. Die 'Temperatur des Thieres lässt sich mittelst eines feinen in den Oesophagus gesteckten Thermometers controliren. In einem Fall steigerte ich durch längeres Erwärmen des Thiers auf ca. $40^{\circ} \mathrm{C}$. die Pulsfrequenz von 45 auf 110,125 und endlich 180 Schläge pro Minute. Gleichzeitig stieg der Mitteldruck von 80 auf $104 \mathrm{~mm} \mathrm{Hg.} \mathrm{Die}$ Pulsschwankung wurde kleiner. Durchspülung des Wärmecylinders mit kaltem Wasser erniedrigte in kurzer Zeit die Pulszahl auf 50 Schläge.

4) Einfluss der electrischen Vagusreizung auf die Herzthätigkeit.

Technische Vorbemerkungen.

Bei den meisten der bisherigen Untersuchungen über die Bedeutung des Nervus vagus für das Froschherz diente zur Fixirung der Resultate die Cardiographie in verschiedener Form. Wo das Manometer zur Verwendung $\mathrm{kam}$, wurde dasselbe mit dem Aortenbogen in Verbindung gesetzt. Damit war in allen Fällen eine Blosslegung dés Herzens oder wenigstens theilweise Eröffnung des Thorax gegeben und darans ergab sich wiederum ziemlich von selbst die Präparation des Vagus in centripetaler Richtung, wie sie z. B. Loewit) beschreibt. Heidenhain ${ }^{2}$ ) schnitt das Herz mit sammt den Vagis aus.

Da es mir bei meinen Versuchen darauf ankam, immer zuerst ein Bild der normalen Verhältnisse zu bekommen, durfte ich natürlich zu Beginn des Versuchs die Vagi weder abschneiden noch anbinden, sondern höchstens bloss-

1) Dies Archiv Bd. XXIX p. 470.

2) Dies Archiv Bd. XXVII p. 384. 
legen; des öfteren erfolgte die Präparation auch erst unmittelbar vor den Reizungen. Ich musste mich also nach einem Verfahren ${ }^{1}$ ) umsehen, vermöge dessen es mir gelang in kurzer Zeit mit der geringsten Gefahr des Blutverlustes oder der Schädigung des. Nerven durch häufige Berührung den Vagus für die Reizung zugänglich zu machen. Ich war desshalb darauf bedacht, den Ort der Präparation möglichst weit vom Herzen weg zu verlegen, indem ich den Vagus (bei Kröten) voin Rücken her aufsuchte. Dabei hatte ich zugleich den Vortheil, dass ich die zum Manometer führende Canüle bequem in die Arteria cruralis einbinden konnte, was bei einer Präparation des Vagus von der Bauchseite her zu grossen Schwierigkeiten bezüglich der Lagerung des Thiers geführt hätte. Diese Versuchsanordnung bot mir weiter die nicht zu unterschätzende Annehmlichkeit, dass die Stelle, wo die Nervenreizungen vorgenommen wurden, sich in grösstmöglicher Entfernung vom Registrirapparat befand und ich somit bei allen Operationen am Nerv nicht durch die Rücksicht auf eventuelle Störung der Curve in der freien Bewegung gehindert war. Bei dem geringen Durchmesser und der grossen Zartheit der Blutgefässe unsrer Versuchsthiere genügt nämlich eine kleine Verschiebung oder Drehung, um die abgeschrägte Oeffnung der Canüle gegen die Gefässwand zu drücken und so einen Verschluss herbeizuführen, der den Werth des Versuchs illusorisch macht.

Die Präparation geschah in folgender Weise: Der Kopf des Thiers wird von einem Assistenten etwas vorgezogen und nach unten gedrückt; die grosse Hautdrüse hinter dem Trommelfell (Parotis, Wiedersheim) wird mit einer Pincette soviel wie möglich emporgehoben und durch einen flachen Schnitt mit einer scharfen (am besten gebogenen) Scheere entfernt. Man muss hierbei sehr vorsichtig zu Werke gehen und die Augen schliessen (was bei einiger Uebung die Sicherheit der Schnittführung nicht beeinträchtigt) oder sich eine Glasplatte vorhalten lassen, da das stark ätzende Secret, das auf Druck mit grosser Kraft ausspritzt, heftig schmerzende Entzïndungserscheinungen auf der Conjunctiva hervorruft. Durch den Schnitt wird ein Theil der Muskulatur des Schädels blossgelegt. Nach hinten schliesst sich an dieselbe eine zusammenhängende Fettmasse (welche jedoch bei verschiedenen Individuen sehr verschieden entwickelt ist), unter und hinter welcher der Lymphsack sich befindet. In dem median und nach vorne gelegenen Winkel, welchen der hintere Rand des Musculus depressor maxillae 2), der übrigens keinen so breiten Ursprung hat wie bei Rana esculenta) bezw. der hintere Schädelrand mit dem Musculus cucullaris bildet, tritt die Arteria cutanea magna, vom Ramus cutaneus vagi und einer Vene begleitet, aus der Tiefe und wendet sich, in dem Fettpolster oberflächlich eingebettet, zuerst etwas lateral, dann nach hinten, um sich über die ganze Länge des Rückens zu verzweigen.

1) Das von Kl ug, Med. Centralblatt 1881 S. 945, angegebene Verfahren eignet sich für unmittelbar folgende Reizung weniger.

2) Ecker, Anatonie des Frosches I. Abtheilung p. 73 u. 85. 
Gleich nachdem sie an die Oberfläche getreten, giebt sie einen un bedeutenden Ast an die Hautdrüse ab. Wenn man die Präparation einige Male ausgeführt hat, findet man leicht diejenige Lage des Hautschnittes, bei der man eine Verletzung der genannten Arterie vermeidet. Gelingt dies nicht, so genügt eine rasche Unterbindung in dem Winkel, wo sie aus der Tiefe steigt, um die Blutung definitiv zu stillen.

Um nun den gesuchten Nerv vollends zu Gesicht zu bekommen, werden unter dem Fettpolster in der Richtung von vorn nach hinten 2 Fäden durchgeführt (dabei wird der Lymphsack eröffnet) und möglichst median und lateral unterbunden, in der Mitte zwischen den Ligaturen durchgeschnitten und der eine Lappen nach der Mittellinie, der andere nach aussen umgeklappt. Nan sehen wir im hintern Theil der Wunde die Schulterblattmuskeln blossliegen. Der vordere Rand derselben bildet mit dem M. cucullaris und dem M. depressor maxillae die Begrenzung des Operationsfeldes. In der Tiefe sehen wir am weitesten nach aussen und unten den M. sternocleidomastoideus, an dessen hinterem Rand die Arteria cutanea magna auf dem darunterliegenden M. petrohyoideus IV verläuft. Unmittelbar an die mediale Seite der Arterie legt sich der Nervus vagus an; noch weiter nach der Mittellinie zu liegt die Vena cutanea magna; der Nerv liegt also zwischen Arterie und Vene, zugleich entspricht sein Verlauf dem hintern Rand des IV. Petrohyoideus ${ }^{1}$ ). Lässt man nun den Kopf des Thieres von einem Assistenten nach der andern Seite drücken und den M. sternocleidomastoideus mittelst eines feinen Häkchens etwas herausziehen, so kann man nach Durchtrehnung einer zweiten Bindegewebsmembran, welche Arterie und Nerv gemeinsam bedeckt, um den letzteren mittelst eines feinen Unterbindungshakens leicht einen Faden herumführen. Abgesehen von dieser letzten Manipulation braucht der Nerv während der ganzen Präparation nicht ein einziges Mal berührt zu werden.

Bei Schlangen präparirte ich die Vagi natürlich von der Bauchseite. Bei diesen Thieren findet sich eine Verschiedenheit zwischen der linken und rechten Seite. Links verläuft der Vagus zwischen Carotis und Jugularvene durch Bindegewebe mit denselben verbunden; rechts schliesst er sich der Vene an, während die Arterie in die Tiefe hinter der Lunge liegt. Nach der Präparation wurde die Wunde bis auf Weiteres mit einem in physiologische Kochsalzlösung getauchten Wattebausch bedeckt.

Zur Reizung diente ein gewöhnliches D u Bo is'sches Schlitteninductorium meist ohne Fisenkern, das durch ein Daniell'sches Element bedient wurde, und gewöhnliche Hakenelectroden aus feinem Kupferdraht. Während die Electroden an den Nerv angelegt wurden, war der secundäre Kreis durch eine an der secundüren Rolle selbst angebrachte Nebenschliessung abgeblendet; sollte die Reizung beginnen ${ }^{2}$ ) so wurde die Nebenschliessung geöffnet.

1) Ecker, l. c. II. Abtheilung p. 16.

2) Der Anfangs- und Endpunkt der Reizung wurden in der Regel vorher auf dem berussten Glanzpapier markirt. Das benutzte Kymographion

E. Pflüger, Archiv f, Physiologie. Bd. XLIV. 
Nie reizte ich den Nerv in seiner Continuität, derselbe wurde immer erst möglichst nahe an seinem Austritt aus dem Schädel abgebunden und central von der Ligatur abgeschnitten. Um den Erfolg der Durchschneidung zu controliren, wurde entweder unmittelbar nach derselben ein Curvenstück gezeichnet, oder dieselbe wurde, während das Manometer die Pulscurve registrirte, an einem vorher markirten Zeitpunkte vorgenommen.

Nach der Durchschneidung des einen Vagus bei erhaltenem anderen erfolgte in all den Fällen, wo der Vagus bei nachheriger Reizung normale Hemmungswirkung zeigte, eine Druckverminderung, welche bei Kröten im Mittel 6, bei Schlangen bis zu $17 \mathrm{~mm} \mathrm{Hg}$ betrug; dieselbe war meist, doch nicht immer, von einer Pulsverlangsamung, sowie von einer Verkleinerung des pulsatorischen Druckzuwachses begleitet. Die Durchschneidung des zweiten Vagus war zweimal von Beschleunigung und Druckerhöhung gefolgt, zweimal ganz wirkungslos.

\section{Resultateder Reizung.}

\section{a. Hemmungswirkung.}

1) Versuche an Kröten.

Das von verschiedenen Forschern zuweilen beobachtete Fehlen der Hemmungswirkung beim Frosehvagus begegnete mir aueh bei drei Exemplaren von Bufo terrestris. In diesen Fällen zeigte sich electrische, chemische (Kochsalzkrystall) und mechanische Reizung gleich unwirksam.

Einen Unterschied zwischen rechtem und linkem Vagus konnte ich weder bei diesen Thieren noch bei solchen, deren Vagus normales Hemmungsvermögen besass, nachweisen.

Die untere Erregbarkeitsgrenze war bei allen Thieren ziemlich gleich, sie lag meist zwischen 100 und $120 \mathrm{~mm}$ Spiralenabstand (bei herausgenommenem Eisenkern). Fig. 17 zeigt die Wirkung einer Reizung des peripheren Vagusstumpfs bei einem

wurde seiner Zeit von Herrn Dr. Hürthle zusammengestellt. Fs besteht aus zwei gewöhnlichen Kymographiontrommeln, welche sich auf eine Entfernung von über 1,5 Meter gegenüber stehen. Die eine Trommel wird durch ein (älteres, leider nicht vollkommenes) Uhrwerk gedreht, die andere bewegt sich passiv mit, indem der über beide gespannte Papierstreif als Transmission dient, ähnlich wie es bei dem Hering'schen Kymographien der Fall ist. Handelte es sich um genaue zeitliche Messungen, so verwendete ich ein ausgezeichnetes nur mit einem Cylinder versehenes Kymographion aus der Albrecht'schen Werkstätte. 
Rollenabstand von $100 \mathrm{~mm}$. Während des Herzstillstands sehen wir den Blutdruck erheblich sinken; die ersten Pulse nach der Reizung sind vergrössert ; sie gleichen den bei der arhythmischen Herzaction beschriebenen ersten Pulsen nach der Pause, und sind der Hauptsache nach auch auf dieselben Ursachen zurtickzuführen.

Dem Beginne des Reizes folgt eine ziemlich lange Latenzzeit; ebenso ist die Nachwirkung eine ziemlich lange. Nicht immer erhalten wir diese Veränderungen.

Coats und Heidenhain (1. c.) baben am Frosch gezeigt, dass der Vagus nicht allein die Frequenz der Herzschläge herabsetzt, sondern häufig auch die Energie des einzelnen Herzschlags vermindert. Der letztere Forscher sowie Loe w it lässt das stärkere Hervortreten der einen oder andern Wirkung wesentlich bedingt sein durch die verschiedene Stärke der angewandten Reize, in der Art, dass die erste Wirkung schwacher Ströme in einer Verkleinerung der systolischen Erhebung besteht. In einem Theil meiner Versuche fand ich diese Angabe auch für Kröten bestätigt. Fig. 18 bietet uns einen Beleg hiefü; in Curve I betrug der Rollenabstand $100 \mathrm{~mm}$, in Curve II, welche wenige $\mathrm{Mi}$ nuten später gezeichnet wurde, $90 \mathrm{~mm}$. Der Untersehied ist augenfällig. 
Franz Hofmeister:

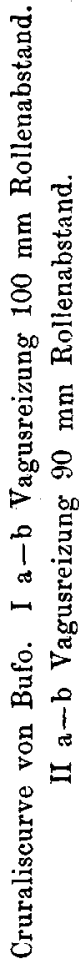


In andern Fällen erhielt ich ein ganz anderes Resultat. Mit Verstärkung der Ströme trat nicht an die Stelle der Pulsverkleinerung eine starke Verlangsamung oder plötzlicher Stillstand; die Frequenz blieb vielmehr nahezn unverändert bestehen, dagegen nahm die Systolengrösse immer mebr ab, so dass schliesslich auf diese Weise ein Her'zstillstand herbeigeführt werden konnte. Heidenhain erzielte dies Resultat durch passende Wahl der Reizstärke und Reizzahl, indem er einzelne schwache Doppelschläge in regelmässigen Pausen durch den Nerv schickte; ganz anders gestaltete sich die Sache bei meinen Versuchen. Die Erscheinung trat auf, ganz unter denselben Umständen, unter denen bei einem andern Thier Herzstillstand erfolgte; sie beruhte also rein auf individuell verschiedener Erregbarkeit.

Bei einer dritten Reihe von Versuchsthieren endlich vermochten selbst sehr starke Ströme nicht die Pulse ganz zum Verschwinden zu bringen. Durch langdauernde starke Reize war noch eine Verlangsamung der Herzaction um 1-2 Schläge in 10 Secunden zu erreichen. Fig. 19 giebt ein Beispiel hiefür. An

Fig. 19.

Cruraliscurve von Bufo. a-b Vaguszeizung bei $40 \mathrm{~mm}$ Rollenabstand.

den letzterwähnten Thieren machte ich ferner die Beobachtung; dass nach wiederholter starker Reizung, wenn also die Erregbarkeit des Nerven vermuthlich etwas gesunken war, die gleiche Stromstärke, welche zuvor eine erhebliche Verkleinerung der pulsatorischen Druckerböhung erzeugt hatte, jetzt dieselbe nur um weniges herabzusetzen vermochte. Ausserdem $\mathrm{Heidenhain} \mathrm{giebt}$ an, dass fur Erzielung der Systolenverkleinerung ohne Frequenzabnahme, „schon etwas ermüdete Herzen am günstigsten seien“. Ich glaube, wir können dafür auch setzen: ermüdete Vagi; denn ich habe in Fällen, wie die vorhin erwähnten, wo stärkere Reizung geringeren Erfolg hatte, von einem Ermatten der Herzthätigkeit nichts bemerken können. Halten wir diese Ergebnisse zusammen mit der Thatsache, dass bei Thieren, deren Vagi ausgeprägte Hemmungswirkung zeigen, die Herabsetzung der Pulsgrösse 
wesentlich als Folge schwacher Reize auftritt, so kommen wir zu dem Ruickschluss, dass bei denjenigen, bei welchen diese Pulsverkleinerung als einzige Wirkuug auch stärkerer Ströme sich einstellt, die Erregbarkeit der Hemmungsfasern des Vagus eine geringere sein muss. Wir hätten demnach folgende absteigende Stufenleiter der Erregbarkeit des Vagus beziehungsweise seiner verschiedenen Fasern:

1) Höchster Grad der Erregbarkeit. Vollständige Hemmungswirkung, das heisst bedeutende Frequenzabnahme oder sofortiger diastolischer Herzstillstand bei stärkeren Reizen und Pulsverkleinerung bei schwächeren.

2) Geringerer Grad der Erregbarkeit. Herzstillstand durch allmähliche Verkleinerung der Systole bis zum Verschwinden derselben (bei starken Reizen) obne grosse Frequenzabnahme.

3) Noch geringerer Grad der Erregbarkeit. Ledig. lich Verkleinerung der Systole (selbst sehr starke Ströme erzeugen keinen Herzstillstand).

4) Als letates Glied der geringsten Erregbarkeit schliesst sich von selbst an: Vollständiges Fehlen jeglicher Hemmungswirkung, sowohl jeglicher Frequenzabnahme als auch jeglicher Pulsverkleinerung.

Meine Versuche über Vaguswirkung bei Kröten fielen mit Ausnahme eines einzigen in die Monate August und September (bei jenem einen am 16. VII. angestellten Versuche war die Hemmungswirkung sehr ausgeprägt). Wenn die von Borisowitsch $\left.{ }^{1}\right)$ und andern gemachte Angabe, dass bei Fröschen im Spätsommer die Vagusreizung ihren hemmenden Einfluss aufs Herz verliert, auf Kröten abertragen werden darf, woran bei der sonstigen Gleichheit der Erscheinungen kaum zu zweifeln ist, so liegt die Vermuthung sehr nahe, in den oben geschilderten vier Erregbarkeitsstufen Uebergangsstadien zu erblicken, eine Vermuthung, der wir um so bereitwilliger zu folgen geneigt sind, als wir uns eine durch die Jahreszeit, also die allmähliche Aenderung der gesammten Lebensbedingungen des Thiers herbeigefübrte Umgestaltung physiologischer Verbältnisse nicht unvermittelt entstanden denken können. Leider konnte ich diesen Gedanken nicht weiter verfolgen, da ich gegen Ende September wegen der Ungunst des Wetters keine Versuchsthiere mehr bekam.

1) Hofmann a. Schwalbe, Jahresberichte etc., Bd. II, p. 483. 
Wo sich die Erregung der Nerven nur in einer Verkleinerung der Systole mit geringer Frequenzabnahme äusserte, war auch die Drucksenkung begreiflicher Weise viel unbedeutender als bei ausgesprochenem diastolischen Stillstand. Die Wiederherstellung des normalen Blutdrucks erfolgte dann meist nicht durch vergrösserte Pulse; dieselben nahmen vielmehr allmählich wieder an Höhe zu.

Die von Heidenhain angegebene und von Loewit bestätigte Thatsache der "verstärkten diastolischen Erschlaffung" konnte ich nicht direct beobachten, muss dieselbe aber aus dem Auftreten vergrösserter Pulse nach oder während der Reizung erschliessen.

Aus der Thatsache, dass durch die Vagusreizung die diastolische Erschlaffung verstärkt wird, folgt ohne weiteres, dass bei normaler Herzaction die Erschlaffung nicht so vollständig ist, als sie sein könnte. Heidenhain hat diesen Schlnss gezogen, lässt jedoch die Frage nach der Ursache der unvollständigen Erschlaffung des Ventrikels unter normalen Verhältnissen offen. Loewit nimmt ebenso wie Gaskell einen tonischen Erregungszustand des Herzens auch während der Diastole an. (Siehe ubrigens den Schluss unserer Arbeit.)

Es würde hiernach das Herz unter gewöhnlichen Umständen, wenn wir es mit einem Skeletmuskel vergleichen, einem sehr ermüdeten Skeletmuskel ähnlich sein. So wie dieser geht es auch ganz allmäblich und viel langsamer als ein frischer Muskel in seine Ruhelage $\mathfrak{u b e r}$ und erreicht dieselbe um so weniger vollständig; je früher es wieder durch einen neuen Reiz aus derselben herausgerissen wird. Auch die von Heidenhain (l. c.) mitgetheilte Curve XV scheint für diese Auffassung zu sprechen. Denn die Erschlaffung erfolgt hier gegen das Ende zu ausserordentlich langsam (10 $\mathrm{mm}$ etwa in 2 Secunden), während sie im Anfange des Versuchs - genau lässt es sich nicht nachmessen - jedenfalls viel schneller ( $7 \mathrm{~mm}$ ungefähr in $1 / 2-1 / 10$ Secunde) sich vollzieht.

2) Versuche an Ringelnattern.

An diesen Thieren konnte ich auf Reizung mit Inductionsströmen niemals eine andere Wirkung der Vaguserregung constatiren, als die Hemmungswirkung im alten Sinne des Worts, d. h. Pulsverlangsamung mit Vergrösserung der Einzelpulse oder Herzstillstand und nach demselben einige vergrösserte $P$ ulse, welche den 
Uebergang zur Norm vermittelten. Meist sind die Pulse, welche dem Herzstillstand vorangehen, sowie die ihm unmittelbar folgen, verlangsamt, in der Art, dass die Dauer der Panse mit der Entfernung vom Herzstillstand (nach vor- und rïckwärts) immer mehr abnimmt.

Der untere Schwellenwerth für die Erregung lag im Durchschnitt bei einem Spiralenabstand von etwa $100 \mathrm{~mm}$ (ohne Eisenkern). Die Latenzperiode scheint von noch längerer Dauer als bei Kröten: bei kurzen schwachen Reizen sah ich die Wirkung oft erst am Schluss oder noch später eintreten. Die Nachwirkung ist ebenfalls eine bedeutende. Eine „positive Nachwirkung“ d. h. eine gleichzeitige Steigerung der Pulsfrequenz und Pulsgrösse (Heidenhain l. c.) habe ich bei diesen Thieren nicht beobachtet. Die Reizung ${ }^{\circ}$ mit Inductionsströmen blieb nie obne Wirknng. Auch zeigte sich in der Wirksamkeit des rechten und linken Vagus kein Unterschied. Fig. 20 und 21 veranschaulichen dic Reizwirkung. In einem Fall, wo ich mit constanten Strömen reizte (4 Daniell, in der Nebenschliessung ein Siemens'scher Rheostat) erhielt ich bei absteigendem Strom, als der Widerstand in der Nebenschliessung 2000 Siemens betrug, als Nachwirkung eine Pulsverkleinerung, wie sie Fig. 22 zeigt. Von $a-b$ dauert die Reizung. Weiter habe ich die Wirkung constanter Ströme nicht untersucht. (Siehe S. 421.)

\section{b. Beschleunigende Wirkung der Vagusreizung.}

In einem der im vorigen Abschnitt erwähnten Fälle, in dem die Hemmungswirkung nach Reizung des einen wie des andern Vagus vollstïndig ausblieb, bemerkte ich im Gefolge eines stärkeren Reizes eine Vermehrung der Pulsfrequenz von 38 auf 56 Schläge in der Minute. Ausserdem konnte ich bei erhaltener Hemmungswirkung mitunter als Nachwirkung eine Beschleunigung der Pulsfolge constatiren (,positive Nachwirkung“ nach Heidenhain). In der grösseren Zahl der Versuche jedoch fehlte sie, ohne dass ich mir zunächst über den Grund dieser Verschiedenbeit Rechenschaft geben konnte. In der verschiedenen Stromstärke konnte die Ursache nicht liegen, da ich häufig bei sehr starken Strömen keine beschleunigende Nachwirkung erhielt. Eine eingehendere Untersuchung der Frage fuhrte zu einem sehr merk- 
Fig. 22.

Aortenkurve von Tropidonotus. $a-b$ Vagusreizung mit constantem Strom absteigender Richtung (in der Nebenschliessung Widerstand von 2000 Siemens) (die untere Curve ist die unmittelbare Fortsetzung der obern).

wïrdigen Ergebniss. Um die Wirkung der von Schiff und Moleschott, Heidenhain und anderen statuirten Beschleunigungsfasern möglichst rein zu bekommen, beseitigte ich den störenden Einfluss der hemmenden Elemente durch subcutane Injection von Atropin sulf. (bei manchen Thieren genügte $0,1 \mathrm{cem}$ einer 0,05 procentigen Lösung $=1 / 20 \mathrm{mg}$ zur vollständigen Lähmung der Hemmungsfasern). Zur Reizung verwandte ich immer den rechten Vagus. Da ich bezüglich der herzhemmenden Wirkung einen Unterschied zwischen beiden Seiten nicht gefunden hatte, wollte ich mir zunächst die Mühe der Präparation auch des zweiten Nerven ersparen.

Das uberraschende Resultat einer grossen Zahl von Reizungen mit schwachen und starken Strömen war ein vollständiges A usbleiben jeglicher Pulsbeschleunigung. 
Der Umstand, dass die Angaben Heidenhains sich auf das ausgesehnittene Herz beziehen, liess mich auf den Gedanken kommen, ob vielleicht in dieser Verschiedenheit der physiologischen Bedingungen die Ursache für die Differenz der Versuchsergebnisse zu suchen sei. Durchschneidung des Ruickenmarks zwischen fünftem und sechstem, sowie zwischen drittem und viertem Wirbel änderte nichts an dem Resultate. Ich musste also weiter centralwärts suchen. Um unnöthiges Probiren zu vermeiden, ging ich radikal vor und zerstörte den central von der Schnittstelle gelegenen Theil des Rückenmarks sowie das Gehirn. Die nächste Vagusreizung (bei $70 \mathrm{~mm}$ Rollenabstand) bestätigte meine Vermuthung; sie brachte eine Frequenzvermehrung um 7 Schläge in der Minute. Es galt nun die Nervenbabn, durch welche diese regulatorischen Vorgänge vermittelt wurden, ausfindig zu machen. Eine nochmalige genaue Prifung der fribheren Versuche ergab, dass in allen Fällen, wo die beschleunigende Nachwirkung sich gezeigt hatte, beide Vagi abgeschnitten waren. Ich stellte nun einige Versuche an, in der Art, dass ich zuerst den einen Vagus bei erhaltenem andern reizte, dann den zweiten abschnitt und abwechselnd den rechten und linken reizte. Ausnahmslos fehlte vor Durchschneidung des zweiten Vagus die Beschleunigungswirkung; nach derselben war sie da. Ein Unterschied zwischen den beiden Vagis ist auch hier nicht zu constatiren. Wir kommen demnach zu dem Schluss, dass bei Kröten die Reizung des einen Vagus nur dann eine Beschleunigung der Herzaction zur Folge hat, wenn der andere durchsehnitten ist. Wir müssen also annebmen, dass durch die Reizung eines Vagus, welche an sich Beschleunigung: hervorriefe, im Herzmuskel Veränderungen gesehaffen werden, der Art, dass eine Erregung centripetaler Fasern des andern Vagus erfolgt, welche im nervösen Centrum einen der Beschleunigung entgegenwirkenden Impuls hervorruft, der natürlich auch wieder in dem unverletzten Vagus aber centrifugal dem Herzen zugeleitet wird. Eine andere Erklärung für diese Thatsache vermag ich wenigstens nicht zu geben.

Wenn Heidenhain und Loewit diese Erscheinung (vorausgesetzt, dass sie beim Frosch auch vorhanden ist) nicht beobachtet haben, so kann uns.dies nicht wundern, da ersterer am ausgeschnittenen Herzen arbeitete, letzterer zu Beginn des Versuchs (dies glaube ich wenigstens aus den l. c. pag. 471 iber die Prä- 
paration des Vagus mitgetheilten Bemerkungen schliessen zu dürfen) beide Vagi durchschnitt. Auch Klug ${ }^{1}$ ) bat bei den Versuchen, welche ihn zur Annahme beschleunigender Elemente im Vagusstamme fiihrten, beide Vagi durchschnitten. Leider ist aus seiner ersten Arbeit ${ }^{2}$ ) uber diesen Gegenstand, in welcher er zu einem entgegengesetzten Resultat kam, nicht zu ersehen, ob den electrischen Vagusreizungen überhaupt eine Durchscbneidung voranging. Auffallend ist, dass die compensatorische Thätigkeit des andern Vagus auch nach Atropinisirung ungeschwächt bestehen bleibt. Wir können, um diese Thatsache zu erklären, an verschiedene Möglichkeiten denken. Wir könnten annehmen, dass die Fasern, welche die beschleunigungsunterdrückende Erregung leiten, mit den gewöhnlich als Hemmnngsfasern bezeichneten nicht identisch seien, oder, wie etwas ähnliches bereits Heidenhain in seiner Abhandlung uber die arhythmische Herzthätigkeit andeutet, das Atropin eben "nicht alle zı dem intracardialen Hemmungsmechanismus gehörigen Theile lähmt" 3).

Für die Hemmungswirkung liess sich eine ähnliche (vielleicht theilweise) compensatorische Thätigkeit des zweiten intacten Vagus nicht nachweisen.

Die Angaben Heidenbains bczliglich der langen Dauer der Beschleunigungswirkung treffeu auch fiir das unter normalen Bedingungen belassene Herz zu. Ebenso kann ich für Kröten bestätigen, dass zur Erzengung der Beschleunigungswirkung stärkere Ströme nothwendig sind als zur Herbeifuhrung der Herzhemmung.

Die Wirkung der Beschleunigungsfasern auf die Grösse der Herzbewegung anlangend bestehen zwischen den Angaben von Heidenbain und Loewit bedeutende Differenzen.

Der erstere Forscher sieht mit der Beschleunigung stets eine Vergrösserung des Einzelschiags einhergehen, letzterer stets eine Verkleinerung. Meine Versuche am normalen Herzen ergaben in Uebereinstimmung mit Loewit eine (allerdings unbedeutende) Verkleinerung der Einzelpulse. Aller Wahrscheinlichkeit nach ist wohl die verschiedene Art der Versuchstechnik hiefur verantwort-

1) Medicin. Cntralblatt 1881, p. 945.

2) Du Bois-Reymond's Arch. 1880, p. 506.

3) Ich bemerke, dass die stärkste von mir gegebene Dosis Atropin 1 C.C. der $0,05 \%$ igen Lösung $=0,5 \mathrm{mg}$ betrug. 
lich zu machen (s. Loewit l. c. S. 499-501), indem Heidenhain eben mit dem leeren, entbluteten, Loewit und ich aber mit dem blutgefullten Herzen ${ }^{1}$ ) arbeiteten ${ }^{2}$ ).

Fasse ich hienach die. Ergebnisse meiner eigenen, sowie die fremder Untersuchungen zusammen, so kann man - indem ich hier wesentlich einen Gedankengang von Herrn Professor Grützner wiedergebe - betreffs der verschiedenen im Vagus befindlichen Fasern ${ }^{3}$ ) zu folgender Anschaung gelangen:

Zunächst giebt es zweierlei Fasern im Vagus, ich will sie 1) Verstärkungs-, 2) Schwächungsfasern nennen. Sie sind als Antagonisten zu betrachten und können je nach ihrer Erregung folgende Zustände in der Herzthätigkeit erzeugen:

1) Die Verstärkungsfasern werden gereizt: Die Systole vergrössert sich.

2) Weder Verstärkungs- noch Schwächungsfasern werden gereizt: Es bestebt die normale von aussen unbeeinflusste Her\%thätigkeit.

3) Die Verstärkungsfasern werden nicht gereizt, die Schwächungsfasern schwach: Die Systole verkleinert sich.

4) Die Verstärkungsfasern werden nicht, die Schwächungsfasern stärker gereizt: Die Systole des Herzens wird auf Null reducirt, das Herz steht also in Diastole still; dieselbe ist aber keine vollkommene.

5) Die Verstärkungsfasern werden nicht gereizt, die Schwächungsfasern maximal: Lie Diastole wird vollkommen.

Wenn man sich, wie dies Grützner bei der verschieden starken Zusammenziehung eines Körpermuskels in Folge verschicden starker Reize thut, diese Vorgänge wesentlich quantitativ

1) Siehe hierüber auch Marey, Circulation du sang, Paris 1881, der p. 95 den auffälligen Unterschied in der Art der Zusammenziehung des leeren und des vollen Herzens in höchst lehrreicher und überzeugender Weise zur Anschauung bringt.

2) Auf die interessanten Untersuchungen von Loewit (l. c.) über die Wirkung verschieden gerichteter Ströme konnte ich nicht mehr eingehen; bemerkt sei, dass ich stets möglichst weit vom Querschnitt entfernt reizte.

3) Damit soll nicht behauptet werden, dass die genannten Eigenschaften nothwendig an besondere Fasern gebunden sein müssen; ein und dieselbe Faser könnte z. B. nach der Art und Stärke ihrer Erregung oder ihrer Erregbarkeit verschiedene Endapparate reizen u. s. f. 
verschieden denkt, $d$. h. wenn man annimmt, dass die verschiedenen contractilen Elemente des Herzens keineswegs von derselben Erregbarkeit sind und nicht alle insgesammt in gleicher Stärke bei einer Systole thätig sind, so würde man sich etwa folgendes Bild von jenen eben erwähnten fünf verschiedenen Herzthätigkeiten machen können:

Bei Zustand 1) werden a 11 e Muskelelemente des Herzens auch die sonst in Reserve befindlichen - zur Thätigkeit herangezogen; bei Zustand 2) die für gewöhnlich thätigen ausschliesslich der Reservemuskeln; bei Zustand 3) nicht alle in der Norm thätigen, bei Zustand 4) nur noch äusserst wenige; bei Zustand 5) gar keine. Es sind a l l e völlig erschlafft.

Man sieht, dass man, ohne den Thatsachen Zwang anzuthun, so eine sich von selbst ergebende Stufenleiter in den Erscheinungen auffindet. Nur Betreffs des Zustands 5 sei noch bemerkt, dass von verschiedenen Forschern hier vielleicht auch eine Activität, also eine active Erschlaffung angenommen wird. Ich möchte diese Anschauung zur Zeit nicht vertreten. Man hat sich nämlich nur an die interessante Beobachtung von Gaskelli) zu erinnern, dass ein ruhender und scheinbar vollständig erschlaffter Herztheil in Folge von Vagusreizung ein electrisches Verhalten zeigt, als sei er vorher thätig gew e se n, aber niemals so, als sei er thätig geworden. Und wenn die Erschlaffung in Folge einer bestimmten Thätigkeit, einer Action des Muskels zu Stande käme, so sollte man doch einen Actionsstrom, aber nicht das Entgegengesetzte sehen. Ich finde es also natürlicher, diese Vaguswirkung mit einer voll k o m me $\mathrm{n} n$, alle Muskelelemente erfassenden Erschlaffung in Verbindung zu bringen.

Weiterhin finden sich im Vagus neben jenen zwei oben erwähnten Faserarten noch zwei andere, ich will sie regulatorische oder Anslösungsfasern nennen; sie beeinflussen lediglich die Frequenz des Herzschlags und zerfallen naturgemäss in 3) Verlangs a m ung $\mathbf{s}=$ und 4) Bes chle unigu $\mathrm{ng} \mathbf{s}$ fasern. Das Herz ist zwar aus sich selbst heraus rhythmisch thätig, aber, wie allbekannt, kann seine Schlagzahl durch Vagusreizung erhöht und herabgesetzt werden; ersteres, wenn man eben die Beschleuniger, letzteres, wenn man die Verlangsamer reizt. Der Rhythmus der Herzaction wird an $\mathrm{mitelbar}$ nur durch die letztgenannten,

1) Festschrift zum 70. Geburtstage Carl Ludwigs; Leipzig 1887, p. 15. 
nicht durch die Schwächungs- und Verstärkungsfasern beeinflusst, mittelbar natïrlich allerdings, indem die Art und Dauer einer einzelnen Systole oder Diastole verändert wird. Jene erstgenannten Nerven stellen das Herz auf eine bestimmte Thätigkeit ein, sie bestimmen gewissermaassen die Zabl der Kämpfer, die an dem Kampfe theilzunehmen haben; den Befehl zum Kampf selbst aber giebt das Herz für sich und einen Einfluss hierauf, d. b. auf den Beginn des Kampfes üben von aussen her die Verlangsamungsund Beschleunigungsnerven aus.

Diese baben aber ihrerseits $\mathrm{u} \mathrm{n}$ itte $\mathrm{lb}$ a $r$ keinen Einfluss auf die Stärke der Herzcontractionen, sondern sie helfen oder erschweren nur die Auslösung des Mechanismus, geradeso wie ich mit einem schwach oder stark geladenen Gewehr auch schneller oder langsamer hinter einander schiessen kann, je nachdem ich - falls eben das Gewehr immer wieder frisch geladen wird häufig oder selten abdrïcke. M i t tel b a r haben die auslösenden Nerven natürlich einen Einfluss auf die Grösse der Herzactionen. Denn wenn das Herz z. B. sich selten zusammenzieht, so hat es Gelegenheit, sich diastolisch besser zu füllen und sich hierauf systolisch um so kräftiger zusammenzuziehen und wenn andererseits die Auslösung zu bäufig erfolgt, so wird in der Regel das Entgegengesetzte eintreten.

Ich glaube nicht, dass jene Annahme von vier verschiedenen Faserarten (s. Anmerkung S. 425) etwas Gekünsteltes an sich hat; denn die Erscheinungen am Herzen sind eben so verwickelt, dass man mit der einfachen, ja an sich so ausserordentlich ansprechenden Widerstandstheorie, wie schon Heidenbain ausfuhrt, keineswegs zu Stande kommt. Jene Annahmen erscheinen mir um so weniger gekünstelt, als auch bei versehiedenen und gerade sehr sinnreichen Maschinen die Auslösung einer Kraftleistung mit der Grösse der Kraftleistung selbst nichts zu thun hat.

Schliesslich sei nocb erwähnt (was ich iubrigens erst nach völligem Abschluss vorstehender Arbeit bemerkt habe), dass auch Pawlow (D u Bois-Rey monds Archiv für Pbysiolog. 1887 S. 556) sich über die centrifugalen Nerven des Hundeherzens folgendermaassen äussert: die Arbeit des Herzens wird von vier centrifugalen Nerven regiert, dem verlangsamenden, beschleunigenden, schwächenden und verstärkenden; in der That eine für mich sehr angenehme Uebereinstimmung der auf so verschiedenen Gebieten und mit ganz verschiedenen Mitteln erworbenen Anschauungen. 